\title{
Large-scale and synoptic meteorology in the south-east Pacific during the observations campaign VOCALS-REx in austral Spring 2008
}

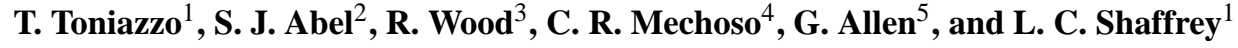 \\ ${ }^{1}$ NCAS, Department of Meteorology, University of Reading, RG6 6BB, UK \\ ${ }^{2}$ Met Office, Exeter, UK \\ ${ }^{3}$ University of Washington, Seattle, USA \\ ${ }^{4}$ UCLA, Los Angeles, USA \\ ${ }^{5}$ University of Manchester, UK \\ Received: 30 November 2010 - Published in Atmos. Chem. Phys. Discuss.: 6 January 2011 \\ Revised: 26 April 2011 - Accepted: 5 May 2011 - Published: 27 May 2011
}

\begin{abstract}
We present a descriptive overview of the meteorology in the south eastern subtropical Pacific (SEP) during the VOCALS-REx intensive observations campaign which was carried out between October and November 2008. Mainly based on data from operational analyses, forecasts, reanalysis, and satellite observations, we focus on spatiotemporal scales from synoptic to planetary. A climatological context is given within which the specific conditions observed during the campaign are placed, with particular reference to the relationships between the large-scale and the regional circulations. The mean circulations associated with the diurnal breeze systems are also discussed. We then provide a summary of the day-to-day synoptic-scale circulation, air-parcel trajectories, and cloud cover in the SEP during VOCALS-REx. Three meteorologically distinct periods of time are identified and the large-scale causes for their different character are discussed. The first period was characterised by significant variability associated with synopticscale systems interesting the SEP; while the two subsequent phases were affected by planetary-scale disturbances with a slower evolution. The changes between initial and later periods can be partly explained from the regular march of the annual cycle, but contributions from subseasonal variability and its teleconnections were important. Across the whole of the two months under consideration we find a significant correlation between the depth of the inversion-capped marine boundary layer (MBL) and the amount of low cloud in the area of study. We discuss this correlation and argue that
\end{abstract}

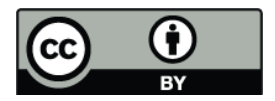

Correspondence to: $\mathrm{T}$. Toniazzo (t.toniazzo@ reading.ac.uk) at least as a crude approximation a typical scaling may be applied relating MBL and cloud properties with the large-scale parameters of SSTs and tropospheric temperatures. These results are consistent with previously found empirical relationships involving lower-tropospheric stability.

\section{Introduction}

The marine stratocumulus ( $\mathrm{Sc}$ ) systems of the subtropical anticyclones cause a large negative radiative forcing for the global climate system (Klein and Hartmann, 1993). They are also associated with oceanic upwelling systems of enormous biological productivity (e.g. Hastenrath, 1991: Sect. 10.5, and references therein). Such associations make them fundamentally important building blocks of the present-day climate system.

Unfortunately, they are also some of the areas less wellunderstood or well-modelled (cf. the preVOCA assessment of Wyant et al., 2010) in climate science. Uncertainties in top-of-the-atmosphere short-wave forcing from the tropical Sc decks seriously affect the projected climate sensitivity under greenhouse-gas forcing (Bony and Dufresne, 2005). Moreover, climate simulations of present-day (and, by implication, historical) conditions consistently show both large errors in the climatology of these regions (de Szoeke and Xie, 2008) and a high sensitivity of the global tropical circulation to such regional errors (Ma et al., 1996), which are linked with a series of coupled ocean-atmosphere feedbacks and thereby affect both the mean climate and its modes of variability (Toniazzo, 2010). In particular, the modelled Sc

Published by Copernicus Publications on behalf of the European Geosciences Union. 
are sensitive to local feedbacks between radiation and turbulence in the maritime boundary-layer (MBL) that tend to exacerbate errors (Konor et al., 2009).

In part to address some of these issues, a concentrated observational and modelling study has been underway that focuses on the south-eastern Pacific (SEP) off the western coast of South America, where the most persistent tropical Sc decks are found (Klein and Hartmann, 1993). The international research project, called VOCALS (VAMOS ocean-cloud-atmosphere-land study), included an intensive observations campaign in the SEP (VOCALS-REx), between 1 October and 2 December 2008. An introduction to VOCALS, and a detailed overview of VOCALS-REx operations and observations, is provided in Wood et al. (2011).

Our primary goal in this contribution is to provide a meteorological context for VOCALS-REx observations. In doing so we aim to highlight the role of synoptic and large-scale atmospheric forcing in controlling changes to the Sc deck. This question is complementary to and thus addresses one of the core science questions of VOCALS, namely to what extent cloud microphysical processes, including aerosol interaction, affect the cloud cover in tropical Sc areas. Several studies have already highlighted the importance of dynamically forced cloud variability.

Garreaud et al. (2002) have shown that sub-synoptic systems that arise from the interaction between synoptic forcing and the Andean orography significantly affect Sc cover over time-scales of a few days. From their analysis of satellite and sea-level pressure data, George and Wood (2010) have argued that, more generally, sub-seasonal variability in cloud properties is to a significant extent controlled by meteorological conditions. In the context of VOCALS-REx, Rahn and Garreaud (2010b) have shown that the observed variability in MBL depth, and in part of the associated cloud cover, was largely dependent on synoptic forcing in the SEP area. Additional evidence of meteorological controls is given in Zuidema et al. (2009) and Painemal et al. (2010).

By using a variety of observational, reanalysis, and operational analysis/forecast data, in this contribution we synthesise the available meteorological information for the duration of the VOCALS-REx campaign. We provide an exhaustive documentation of the meteorology from sub-synoptic to planetary scales which may constitute a background for future VOCALS modelling case-studies. We then exploit this descriptive analysis to discuss the relationship between the synoptic- and large-scale circulation and the observed state and variability of the MBL and cloud in the VOCALS-REx domain, with the aim to attempt to isolate and quantify, from a large-scale perspective, the dynamically induced part of the observed cloud variability. Reflecting these different aims, the paper is structured in several inter-dependent sections, in an order meant to provide a context for each part of the meteorological analysis we conducted. We summarise them here to provide a guide to the reader.
Section 2 details the data we used for this analysis. In Sect. 3 we provide the background context for VOCALSREx with a description of the mean circulation and the associated typical meteorological conditions for the area of the southern Pacific subtropical anticyclone observed by VOCALS-REx. Section 4 complements this with a description of the mean diurnal variations of the circulation in the SEP, which are of obvious importance for the specific temporal sampling of VOCALS-REx missions. These two initial sections complement the discussion on the general meteorology of the SEP given in other literature (Rahn and Garreaud, 2010a; Zuidema et al., 2009) and is also required in order to provide the context for the subsequent sections in this paper. We then move to the planetary scales circulation in Sect. 5, where we describe its seasonal evolution and its likely drivers for October-November 2008. In Sect. 6 we discuss regional and remote large-scale inter-annual and sub-seasonal anomalies that affected the VOCALS-REx campaign. Section $7 \mathrm{fi}-$ nally focuses on the region of the south-east Pacific sampled during VOCALS-REx, with specific attention to the cloud cover and to the circulation and tracer advection in the lower troposphere and the MBL. This is the part most closely relevant for VOCALS-REx operations and is descriptive in nature, with a nearly day-to-day assessment of the meteorology. We discuss the evolution of the MBL during VOCALSREx and the connection between local and large scales in Sect. 8. This part addresses the broader scientific aims of VOCALS, by investigating how the state of the MBL and of the cloud cover in the SEP are related in a general sense with the synoptic- and planetary-scale conditions. Finally, Sect. 9 summarises our findings and draws conclusions.

\section{Data sources}

We base most of the following discussion on data from the analysis fields and 21-h forecasts (at 3-hourly intervals) of the UK Met Office global operational forecast model (cycle G48, operational from July to November 2008). It uses a 4D-Var variational data assimilation system (Rawlins et al., 2007) which includes perturbation forecasts and adjoint models to obtain the optimal representation of the meteorological conditions within a 6-h data window.

The data incorporated into the best-fit operational analysis include surface-based Synops, GPS, and drifting-buoy observations; rawinsonde (TEMP, PILOT), dropsonde, and aircraft (EIREPS, AMDARS) data; and a large set of satellite observations including GOES, NOAA, QUIKSCAT, METOP-A and the A-train (AQUA and TERRA-Modis). The forecast model is formulated on a regular longitudelatitude grid (Arakawa C-grid) with $640 \times 481$ points with a spacing of $0.5625 \times 0.375$ degrees, giving a resolution of $58.7 \times 41.7 \mathrm{~km}$ at $20^{\circ} \mathrm{S}$. In the vertical, there are $50 \mathrm{lev}-$ els based in a height coordinate which is terrain-following near the surface but changing to constant height (above 
sea-level) above level $30(17.4 \mathrm{~km})$. The dynamical core is based on a non-hydrostatic, two-time level, semi-implicit, semi-Lagrangian high-order (cubic to quintic) formulation (Davies et al., 2005). The boundary layer scheme is a nonlocal surface-forced K-profile scheme based on Lock et al. (2000); the microphysics scheme is based on Wilson and Ballard (1999); and the cloud fraction scheme on Smith (1990). The two-stream radiation scheme, based on Edwards and Slingo (1996), is called every three hours. The model physical parameterisations are similar to those used in the Met Office Hadley Centre atmospheric climate model HadGEM1 (Martin et al., 2006).

A validation of the UKMO global forecast system for the SEP area is given Wyant et al. (2010; the preVOCA study). They find that this system has skill in MBL and cloud forecasts over a time-span well in excess of the 21-h horizon we consider here. The only other operational model to show a good performance among the 6 tested was the ECMWF system. Problems were identified with the representation of MBL adjacent to the South-American coast, where is it too shallow and lacking cloud.

Here we consider data for the whole of October and November 2008. Whenever possible, we base our findings on the data from the operational analyses at 00:00 UTC.

We have also analysed the analysis and forecast fields generated with the limited-area configuration of the UKMO forecast system that was integrated over 37 days (between 14 October and 19 November) over the SEP region (Abel et al., 2010). Abel et al. (2010) provide a validation of the model for this period, and show that, in general, the forecast fields are consistent with in-situ observations when maritime areas well away from the coast are considered. Over such areas, the differences between the limited-area model and the lower-resolution global operational forecast model are quite minor for all the purposes of our discussion. For example, the differences in low-cloud cover, which is one of the more sensitive fields, can be appreciated from Figs. 18 and 22 in Sect. 8. There is generally higher cloud-cover in the limitedarea model, correcting some of the bias in the global model, but the spatial and temporal variations are extremely similar.

Consistently with these results, we mostly focus the present study on the maritime areas of the SEP. We also give a preference for the analysis of the global forecast and reanalysis data over the limited-are products, because they have the desired temporal coverage including all of the VOCALSREx period, and provide a degree of internal consistency across the circulations at all the spatial scales under discussion here.

In addition to UKMO operational data, we use the ERAInterim reanalysis (Simmons et al., 2006) product and operational analyses (cycle 36r4, used here for the backtrajectories) of the ECMWF (European Centre for MediumRange Weather Forecast). The former is used for the discussion of the global climatology for austral Spring. No significant differences between the UKMO operational analyses and ERA-Interim were seen over the October and November 2008 that would impact our discussion, and for consistency we generally show UKMO data for that period.

Finally, we will refer to datasets obtained from the observational activities of the VOCALS-REx campaign. These include cloud-cover estimates from visible and infra-red radiance observations by the NOAA geostationary meteorological satellite GOES-10. In addition, we use ship-based radiosonde profiles, and measurements of SSTs, surface air temperatures and winds (see Wood et al., 2011; cf. also Zuidema et al., 2009; Bretherton et al., 2010), and the satellite-derived SST products OSTIA from the UK Met Office (Stark et al., 2007) and the Optimal Interpolation from NOAA (Reynolds et al., 2002).

\section{The average atmospheric circulation in the SEP}

The VOCALS-REx campaign, which took place in the period between 1 October and 2 December 2008, sampled the eastern flank of the subtropical high pressure system of the southeastern Pacific (SEP).

At the deepest point of the wide bay formed by the southern Peruvian and northern Chilean coast-lines, the town of Arica $\left(18^{\circ} \mathrm{S}, 70^{\circ} \mathrm{W}\right)$ served as the main operational base of VOCALS-REx. Observations were gathered mostly in the vicinity of $20^{\circ} \mathrm{S}$, between $72^{\circ} \mathrm{W}$, near the Chilean coast, and a western-most point at $85^{\circ} \mathrm{W}$ where an oceanographic buoy operated by the Woods Hole Oceanographic Institution is located. Along and within a range of $200-300 \mathrm{~km}$ of the coast, ground-, aircraft- and ship-based activities sampled atmospheric data between $30^{\circ} \mathrm{S}$ and $13^{\circ} \mathrm{S}$. This strip of intensive observations is marked in the panels of Fig. 1 by the thick, dashed white line. Wood et al. (2011) gives a comprehensive description of VOCALS-REx operations.

From a large-scale perspective, the SEP is part of the source region of the surface trade-winds of the southern tropical Pacific (e.g. Hastenrath, 1991), under the descending, radiatively cooling branch of the Walker-Hadley circulation in the Pacific. It is located at the eastern end of the southPacific sub-tropical anticyclone, characterised by steady, divergent surface winds, which intensify near land into a lowlevel jet parallel to the coast. A permanent inversion with extensive strato-cumulus cloud (Sc) separates the cool, moist marine boundary layer (MBL) from the warm and dry free troposphere (FT, Fig. 1). The cool MBL temperatures in the SEP result from a combination of atmospheric and oceanic processes. While orographic blocking increases the static stability and contributes in maintaining the strong inversion capping the MBL (Richter and Mechoso, 2006; Wyant et al., 2010), cool MBL temperatures are consistent with the low moist static energy of the very dry free-tropospheric air above (Takahashi and Battisti, 2007). Within the MBL the flow of cool, dry air over the sea-water generates evaporation, and the Sc cover, stabilised by the inversion, limits 


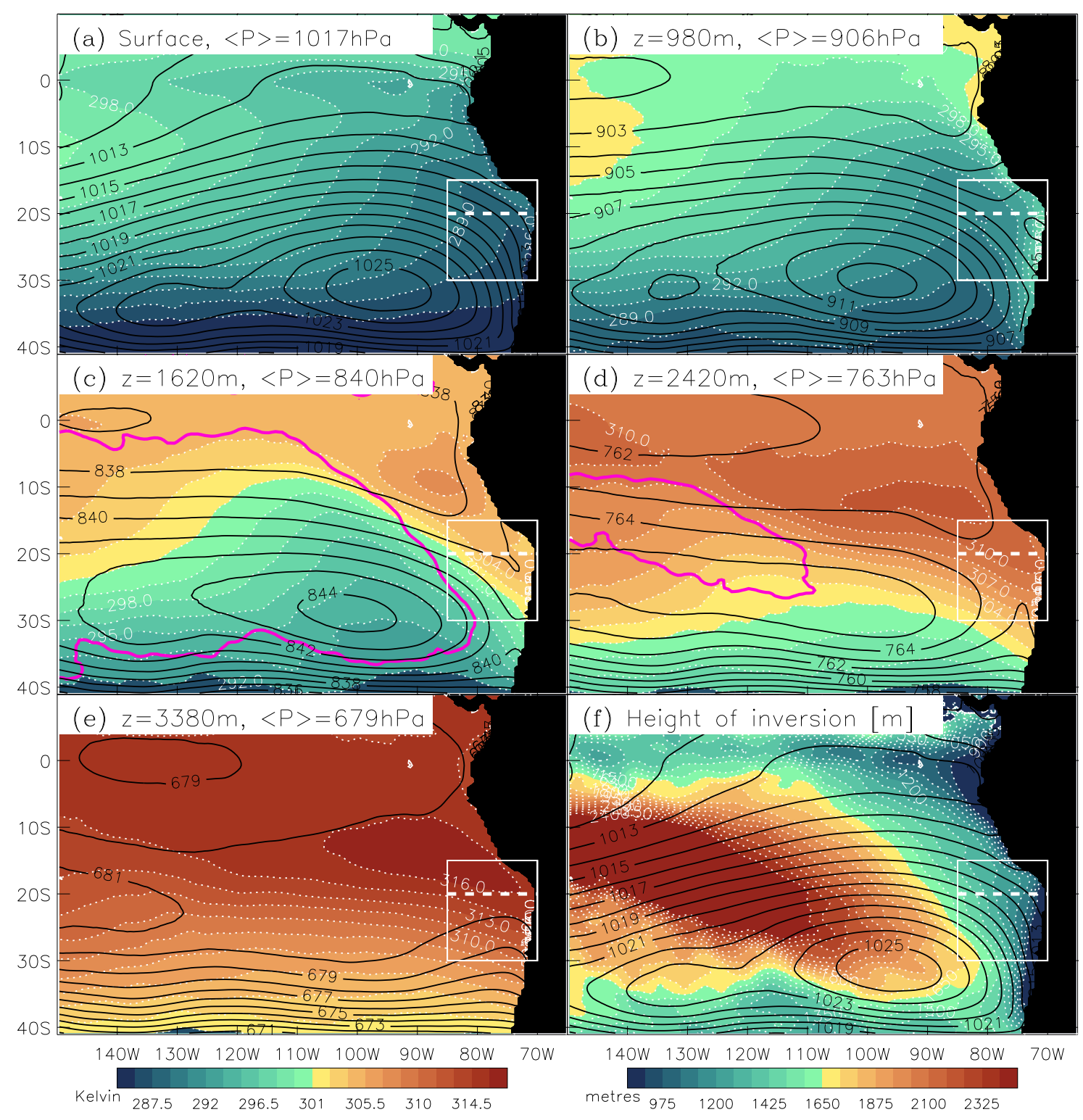

Fig. 1. (a) to (e) Potential temperature (colour-coded, dotted contours, in K) and pressure (full black lines, in hPa) for the OctoberNovember 2008 mean in the south-east Pacific, at the surface and four different altitudes, as indicated. The pink contour lines in the third and fourth panels indicates where the diagnosed inversion intersects the horizontal section. The white box with the thick dashed line along $20^{\circ} \mathrm{S}$ marks the area where VOCALS-REx operations took place. The colour scale is shown in the bar at the bottom of panel (e). (f) Mean height of the diagnosed inversion (colours, in $\mathrm{m}$; colour scale at the bottom of this panel), when present (positive vertical temperature gradient); the black contours show the surface pressure, and are identical to those in panel (a). All data from the UKMO global operational analysis (00:00 UTC).

the short-wave (SW) radiation absorbed by the ocean by an amount of the order of one hundred $\mathrm{W} \mathrm{m}^{-2}$ (e.g. Colbo and Weller, 2007). The positive residual net heat flux into the ocean (Colbo and Weller, 2007; de Szoeke et al., 2010) is offset by cold oceanic advection, aided by the wind-forced coastal upwelling. The relative role of each of these processes to maintain the observed thermal and dynamical state of the MBL in the SEP has long been the subject of active investigation (e.g. Ma et al., 1996; Zheng et al., 2010).
The relationship between the mean atmospheric flow and the thickness of the cool MBL is illustrated in Fig. 1, which shows isobars and isoentropes at various heights, together with the line where the inversion crosses the relevant altitude (thick, pink contour-line in panels $\mathrm{c}$ and $\mathrm{d}$ ). Here and throughout this paper, we diagnose the height of the inversion (Fig. 1f) as the location of maximum vertical gradient in potential temperature within the lower $4000 \mathrm{~m}$ of the atmosphere. For the model fields, this is estimated by first 

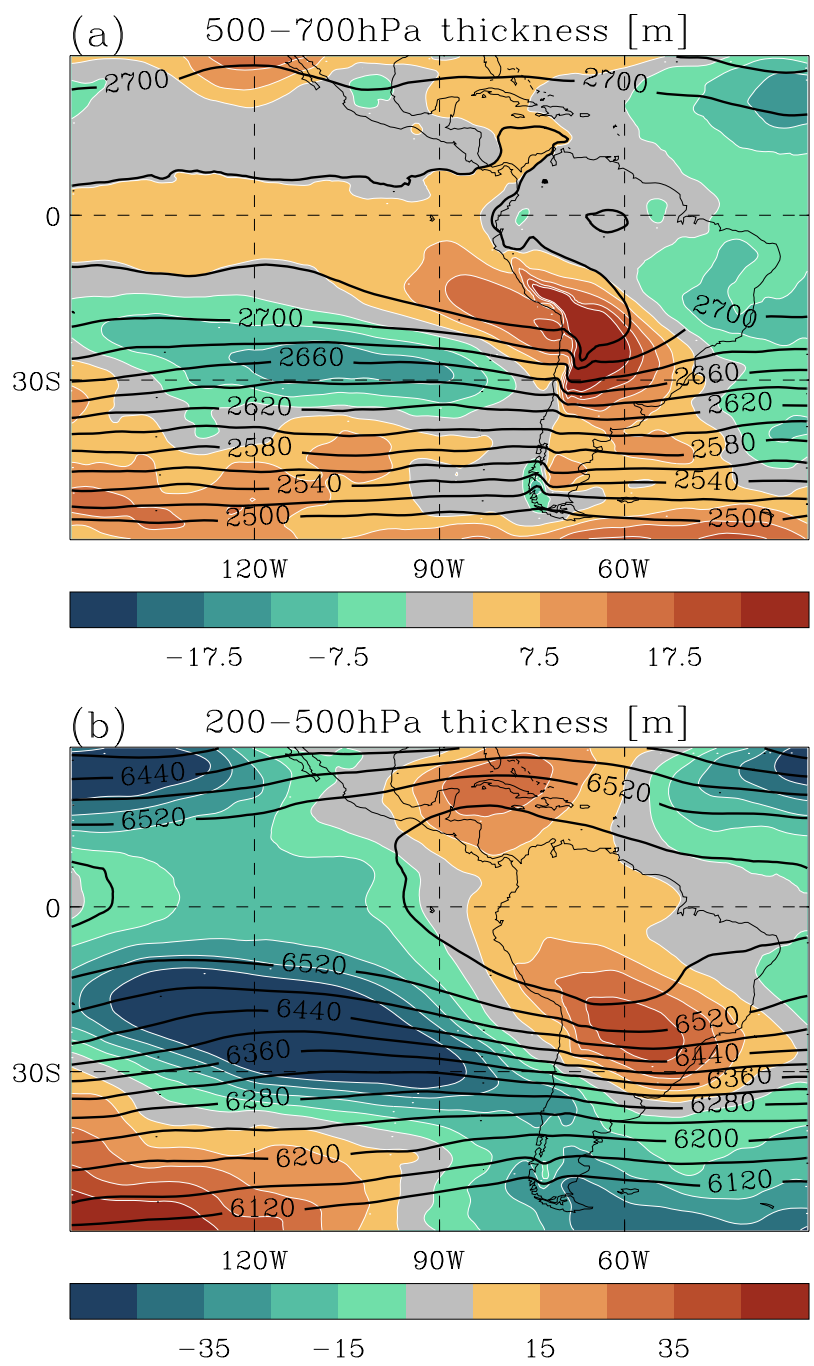

Fig. 2. (a) Total (thick black lines) and zonally asymmetric component (colours) of the 500-700 hPa geopotential thickness fields in the eastern-Pacific/south-American sector. (b) Same as (a), but for the 200-500 hPa thickness. Shown are the time-means for the period between 1 October 2008 and 30 November 2008. For the total thickness, the contour interval is $20 \mathrm{~m}$ in panel (a), and $40 \mathrm{~m}$ in panel (b). Data from UKMO operational analysis.

differences, and the inversion height at any given point in time and space corresponds to one of the model half-levels. The inversion is diagnosed to exist at a given location and time if the vertical gradient of air temperature is positive.

The level of the MBL-top inversion represents the scaleheight of the cold surface anticyclone, which disappears above $700 \mathrm{hPa}$ (Fig. 1e). East of the surface anticyclone, the mean wind veers from a southerly flow in the MBL to westerly flow above $700 \mathrm{hPa}$. At the northern edge of the anticyclone, near $20^{\circ} \mathrm{S}$ where VOCALS-REx took place, the mean MBL winds also have a significant easterly component, while above the inversion in the FT there is a weak mean northerly component. Directional variability is extremely small in the MBL, but it is generally much more pronounced on synoptic time-scales in the FT. To leading order, the thermal wind in the lower troposphere in the SEP reflects thickness variations of the cool MBL (Fig. 1c, d, and f), rather than horizontal gradients in the MBL temperature itself.

The surface flow is dynamically coupled with the subtropical jet stream in the upper troposphere (Fig. 2b). Conditions in the SEP are influenced by the transport of momentum and tracers in and across the jet stream, and their variability is directly affected by baroclinic activity in the southern mid-latitudes. Of particular interest are the occurrences of coastally-intensified cyclones, or coastal lows, which initially develop upstream of the SEP and are affected by the Andean orography. In association with such disturbances, trailing cold fronts are observed as far north as $20^{\circ} \mathrm{S}$ between autumn and spring (Seleuchi et al., 2006; Barret et al., 2009; Rahn and Garreaud, 2010b; a specific case occurred during VOCALS-REx in 23-24 October).

At tropical latitudes, prominent regional features of the circulation in the free troposphere are associated with the heat sources over the elevated topography of the Andes, especially the Peruvian Andes and the Bolivian altiplano, and over areas of moist convection in the Atlantic Warm Pool and the Amazon basin. A Gill-Matsuno (Matsuno, 1966; Gill, 1980) double-anticyclone pattern is visible in Fig. 2b. Its southern branch appears reinforced by the shallower heating over the Andes (Fig. 2a) and results in an anticyclonic turning of the upper-tropospheric winds above the SEP near the continent. As the spring season progresses, insolation and convective activity gradually increase and move southwards, resulting in a strengthening and a southward extension of the pattern shown in Fig. 2b. As well as on the mean circulation, in Sect. 4 we speculate that this also affects the character of the diurnal cycle over the SEP.

The thermally direct, mean cell associated with the Andes clearly appears in the meridional transects shown in Fig. 3, especially near the coast (panel b). Over the lower terrain to the North of the orography, inside the Amazon basin, there is the mean ascent with a deeper structure than that directly above the orography, consistently with moist convection. Over the ocean, radiative cooling of the dry troposphere is generally compensated by subsidence. Near the coast this subsidence is strongly enhanced in the boundary-layer flow over the dry, south- and west-facing orographic slopes, where it is associated with a mean low-level easterly flow which is maintained by the land-sea thermal contrast and represents a continuation of the Chilean coastal circulation (see also Fig. 4). Moving west, the easterly acceleration of the flow is associated with a line of meridional convergence above the inversion at $22^{\circ} \mathrm{S}$ and represents an increased turning of the low-level wind near the coast following the orographic slope.

The dominant circulation feature in the free troposphere is the the subtropical jet-stream (zonal wind colour-coded in Fig. 3a, b), associated with sloping isoentropes (shown as white lines) and extending as far North as $15^{\circ} \mathrm{S}$. In this 

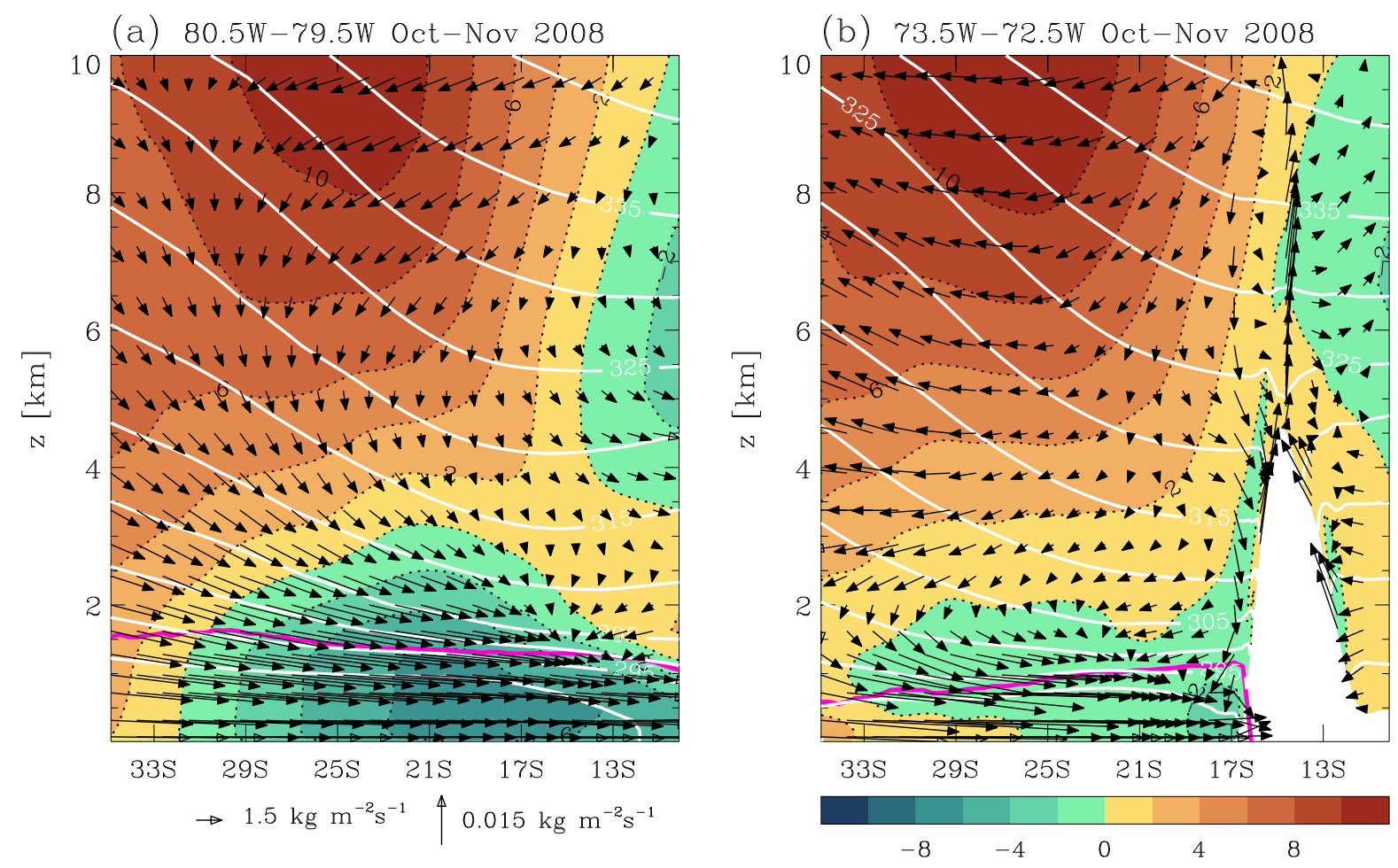

Fig. 3. Meridional transects of mean winds and isoentropes during October-November 2008. Winds are multiplied by density to give mass fluxes. Colour-coding shows zonal wind-speed, with contour interval of $2 \mathrm{~kg} \mathrm{~m}^{-2} \mathrm{~s}^{-2}$; white lines are contours for the dry potential temperature, with a spacing of $5 \mathrm{~K}$. Vector scales for the meridional and the vertical winds are given on the bottom-right. (a) Section along $80^{\circ} \mathrm{W}$. (b) Section along $73^{\circ} \mathrm{W}$. The purple line marks the location of the inversion. Means from 3-hourly UKMO operational analysis and $3 \mathrm{~h}-21 \mathrm{~h}$ forecasts are used.

westerly circulation, which increasingly prevails aloft and offshore, the air-masses lofted in the convective activity over the Peruvian Andes and the Amazon can be carried as far as the VOCALS-REx area around $20^{\circ} \mathrm{S}$ (see later discussion in Sect. 7.2). South of $30^{\circ} \mathrm{S}$ mid-tropospheric ascent becomes noticeable (Fig. 3b), and is associated with the large-scale orographic wave, with a possible contribution from midlatitude baroclinic activity.

Figure 4 shows zonal transects of the mean circulation in the SEP. Considering first the section along $29^{\circ} \mathrm{S}$, the flow is characterised by mean westerlies aloft and easterlies in the MBL. The mean vertical wind is downward everywhere except near the orography, with a distinct poleward barrier flow that allows for vortex stretching. Due to the high stability in the free troposphere, the flow across the Andes is subcritical in terms of its Froude number. It Rossby number however is on average close to one, with a characteristic pressure maximum above and upstream of the ridge in balance with the southerly wind component which extends the barrier flow along the western flanks aloft and eastwards. The increases pressure upstream of the orography associated with the zonal flow affects the pressure distribution at the surface (Richter and Mechoso, 2006) and contributes to the surface divergence in the VOCALS-REx area.
Associated with the south-American land-mass there is a mean temperature front across the mountain chain, and the positive zonal temperature gradient is consistent with the northerly thermal wind component. Along the eastern flanks of the orographic ridge there is a mean updraught that balances the mean diabatic heating, and is associated with a lowlevel southerly flow. On the western slopes, consistently with the prevailing dry conditions, the warmer air temperatures in proximity of the terrain are associated with mean descent, as shown in Fig. 4. The time-average however hides the vigorous diurnal land-sea and mountain breeze circulations, which are associated with descent in the early part of the day and ascent later (see Sect. 4). The presence of a distinct coastal orographic range and of a narrow coastal plateau should be noted here, which are not well-represented in the forecast fields. As a result the near-surface winds near the coast are not accurate (Abel et al., 2010). Such errors may also affect the MBL adjacent to land, which is typically too shallow compared to observations (Wyant et al., 2010; Bretherton et al., 2010).

In the MBL the most prominent feature of the circulation is the southerly coastal jet (Munoz and Garreaud, 2005). The southerly flow in the MBL is maintained by the positive zonal temperature gradient associated with the coastal 

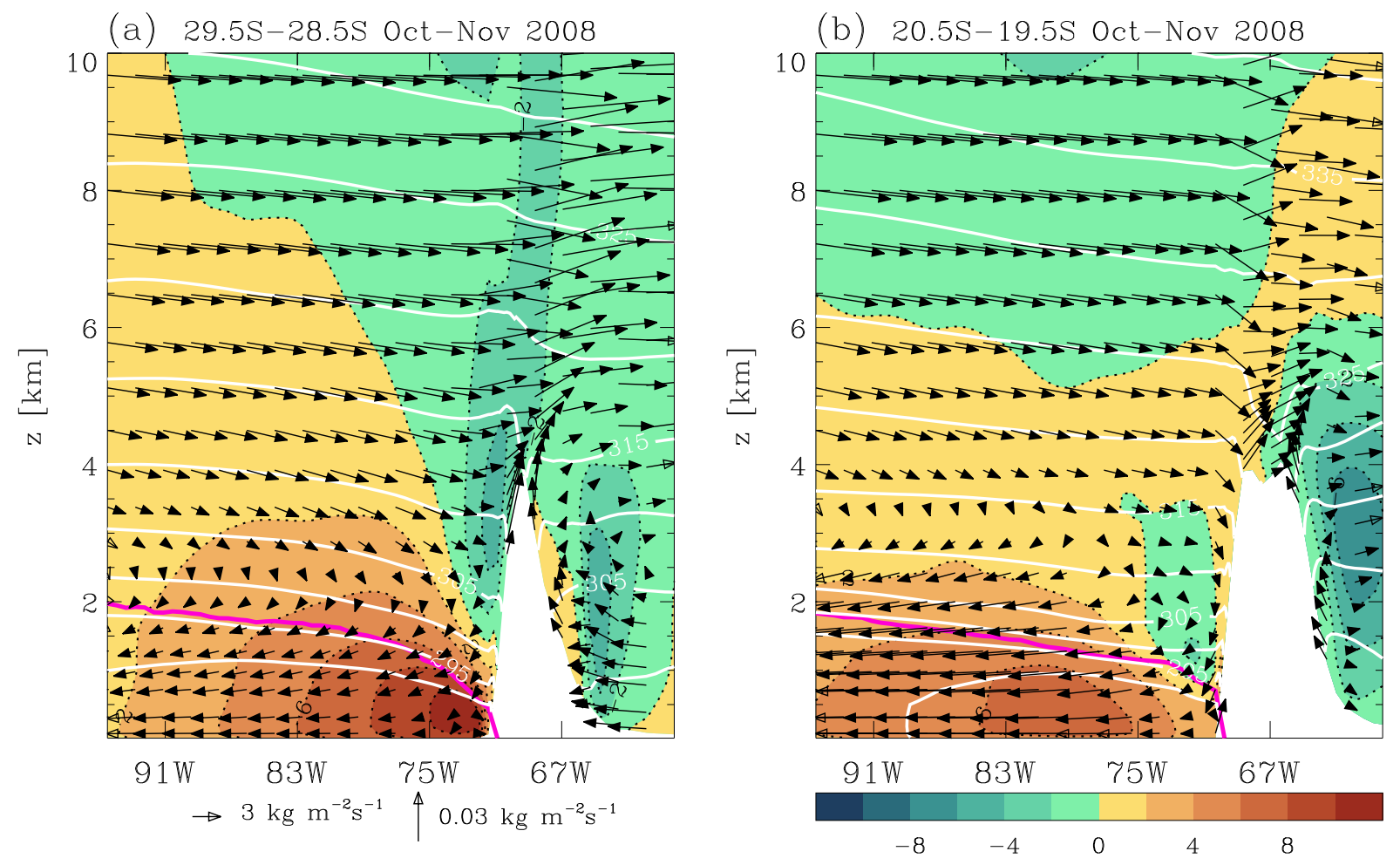

Fig. 4. As in Fig. 3, but for zonal transects along (a) $29^{\circ} \mathrm{S}$, and along (b) $20^{\circ} \mathrm{S}$ (right). Vectors for the vertical and zonal component (scales below panel a), colour-coding for the meridional component. Contour intervals are the same as in Fig. 3.

land-mass, and is consistent with Sverdrup vorticity balance below the level of maximum radiatively driven subsidence (around $500 \mathrm{hPa}$ ).

Along $20^{\circ} \mathrm{S}$, where most VOCALS-REx observations were taken, the mean flow is similar, but with some differences. Near the northern edge of the anticyclone and of the subtropical jet, the MBL wind has turned, with a stronger but also more divergent zonal flow. The meridional component of the flow is less pronounced, with the maximum wind well away from the coast and no persistent coastal jet. Above the MBL and below the level of the orographic ridge the winds are weaker than at $30^{\circ} \mathrm{S}$.

The flow across the orography has smaller Rossby numbers (partly also due to the wider orographic ridge), and is associated with a weak mean southerly component, suggesting planetary potential vorticity balance. Below the level of the ridge, the flow appears blocked, and west of the coast there still is a northerly barrier flow. Close to land the mean flow appears to turn southerly, in association with a strong mean upslope wind, suggesting a mean, buoyant surface density current, which converges over the high plateau of the Bolivian Altiplano. Above the upslope surface current, however, there is strong mean descent, possibly maintaining mass continuity with the zonal flow deceleration aloft. The diabatic forcing associated with the diurnal cycle is likely to be important for the observed mean thermal structure and mean flow. In addition, variability on synoptic time-scales is associated not only with variations in the zonal wind speed, but also with changes, sometimes even in sign, of the meridional and vertical wind components, as the dynamical character of the flow across the orography changes. In general, strengthened zonal flow is associated with enhanced orographic drag and increasing upward and poleward motion over the coastal ocean.

Aloft, the isoentropes have a nearly constant slope and the winds turn northerly everywhere. With a warmer free troposphere and similar MBL temperatures, the inversion is much stronger at $20^{\circ} \mathrm{S}$ than at $30^{\circ} \mathrm{S}$, and the cloud cover more persistent. Additional features of the flow near $20^{\circ} \mathrm{S}$ arise due to the proximity of the Peruvian orography, which is oriented at an angle along the WNW-ESE direction and intercepts the mean southerly flow in the MBL and the lower FT. The circulation near this ridge has a vigorous diurnal cycle, with larger diurnal variations than those associated with the N-S Andean crest.

\section{Diurnal cycle}

Diurnal variations are an important aspect of the meteorology of the tropical south-east Pacific and the Sc deck. In general, changes in thermal stratification are more significant than the slight variations of the circulation over the 

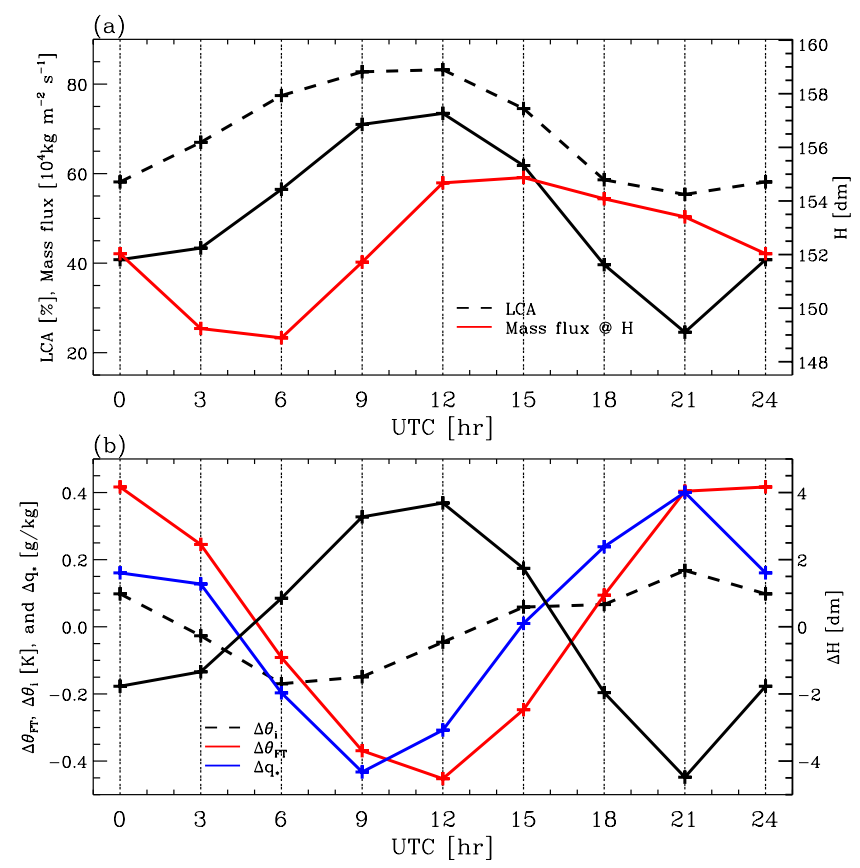

Fig. 5. Mean diurnal evolution of thermodynamic quantities near the inversion in the area $15^{\circ} \mathrm{S}-25^{\circ} \mathrm{S}, 90^{\circ} \mathrm{W}-80^{\circ} \mathrm{W}$. (a) Inversion height (solid black line), cloud amount (broken line), and diagnosed mass entrainment across the inversion (red line) as a function of time of the day. (b) Inversion height anomalies (solid line) together with the lower-tropospheric $(z=2200 \mathrm{~m})$ potential temperature (red line), the MBL-top potential temperature (broken line), and the MBL-top saturation mixing ratio (blue line) as a function of the time of the day. Data from the UKMO operational analyses and $3 \mathrm{~h}-21 \mathrm{~h}$ forecasts.

MBL, owing to the absence of local moist convection. With increased day-time insolation the cloud-top warms and the inversion sinks, with a concomitant reduction in LWP and reduced cloud cover. This process is very important in terms of insolation at the sea surface, as the diurnal cloud-cover minimum occurs a few hours after the maximum in solar irradiation.

The UKMO forecast model relies on MBL turbulence parametrisations to represent the processes that drive the diurnal cycle in the MBL. The simulated a diurnal cycle in fractional cloud-cover and MBL depth is in good qualitative agreement with observations, as long as only marine areas well away from the coast are considered (Abel et al., 2010). The simulated mean diurnal variations have the same qualitative character as an adiabatic night-time lifting and day-time sinking of the cloud top, concomitant with a reduction or increase, respectively, of the lower-tropospheric temperature, and an increase and reduction, respectively, of the cloud liquid water concentration (Fig. 5). This may be contrasted with the variability on synoptic time-scales, which lead (Sect. 8) to a correlation between changes in cloud cover and in the inversion height of the opposite sign.
Superimposed on this locally, radiatively driven diurnal cycle, a number of authors (Garreaud and Munoz, 2004; Wood et al., 2009; Rahn and Garreaud, 2010a) have studied the diurnal modulation of the vertical wind in the SEP by regular gravity-wave pulses propagating offshore from the South-American coast. Such pulses affect the entire depth of the troposphere. They are associated with diurnal heating over the Andean mountain ranges, and they have a measurable effect on lower-tropospheric temperatures and the MBL-depth (Garreaud and Munoz, 2004), and on cloud liquid water (Wood et al., 2002; O'Dell et al., 2008). Figure 6 shows the associated, daily circulation anomalies for a transect along a great circle that intersects the Peruvian Andes. The mid-afternoon mountain breeze maximum (21 UTC) excites a second-baroclinic-mode gravity-wave circulation (00 UTC) that propagates offshore. In the lower troposphere, below the top of the mountain ridge $(5 \mathrm{~km})$, a positive vertical wind anomaly moves in the south-south-west direction with a speed of approximately $25 \mathrm{~m} \mathrm{~s}^{-1}$ (see upward arrows near $20^{\circ} \mathrm{S}$ at $00 \mathrm{UTC}$, and near $26^{\circ} \mathrm{S}$ at $09 \mathrm{UTC}$ in the figure). Maps of vertical wind anomalies highlighting this ascending wave are shown in Garreaud and Munoz (2004) and Wood et al. (2009) using different data sources, model simulations and periods of time, demonstrating that its regular occurrence is robust and well-captured in model simulation, although there can be errors in the exact timing (Rahn and Garreaud, 2010a). Somewhat weaker gravity waves also emanate and propagate zonally from the meridionally oriented ridge of the Chilean Andes (Garreaud and Munoz, 2004).

That a combination of different waves with different origins, phases and time-scales is at play is suggested by the maps of Fig. 7, which shows the phases of the Fourier components of the vertical velocity at $5800 \mathrm{~m}$ with periods of $24 \mathrm{~h}$ and $12 \mathrm{~h}$, as well as the times of maximum and minimum, for the mean diurnal cycle at each location. The phase lines of the 24-h component are broadly parallel to the Peruvian cordillera, suggesting propagation away from it. They indicate a horizontal scale of roughly $3000 \mathrm{~km}$, and tend to correspond to the time of maximum subsidence $(+12 \mathrm{~h})$. The 12-h component appears to involve smaller spatial scales and also smaller phase speeds. While its phase lines are also mainly aligned with the Peruvian coastline, a distinct, meridionally oriented area appears off the Chilean coast, indicating zonal offshore progression. Near the land-mass, its timing is close to the timing of the maximum vertical wind, i.e. anomalous ascending motion. This is consistent with the short duration of the ascending wave discussed by Garreaud and Munoz (2004) which appears to mainly depend on dry the mountain-breeze systems on the western and south-western sloped of the Andes. In addition, Munoz (2008) demonstrated that within about $10^{\circ}$ west of the Chilean coast differential subsidence associated with increased heating of the Andean slopes in the North has a leading-order effect on the diurnal variations of the MBL-depth and the surface pressure gradient, affecting the low-level jet and driving diurnal 

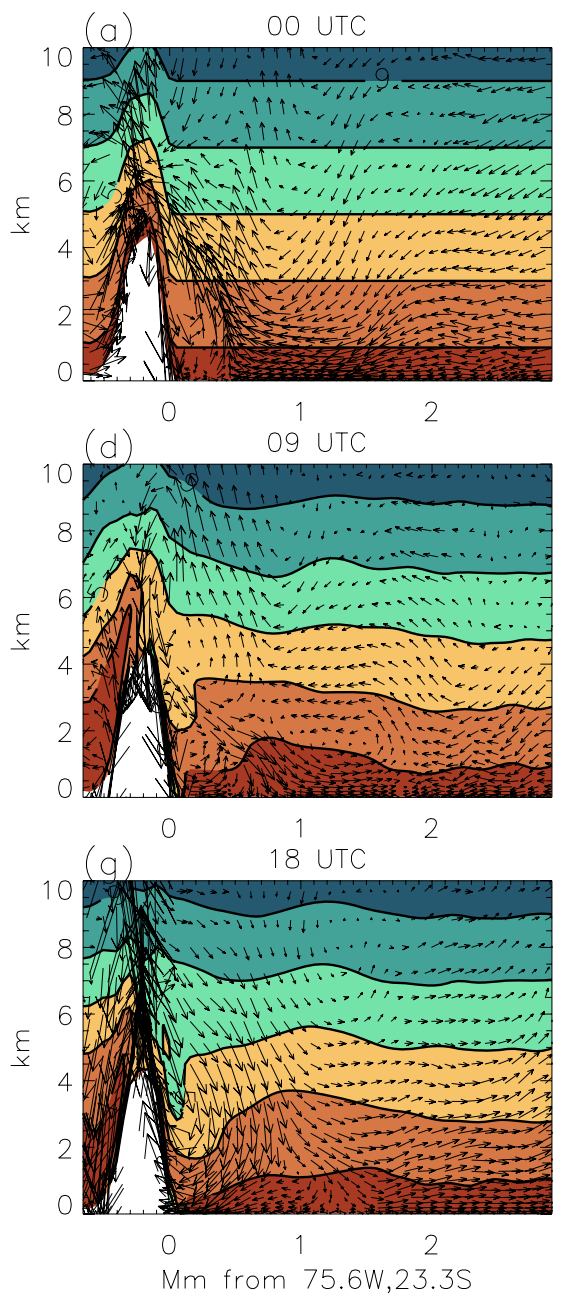
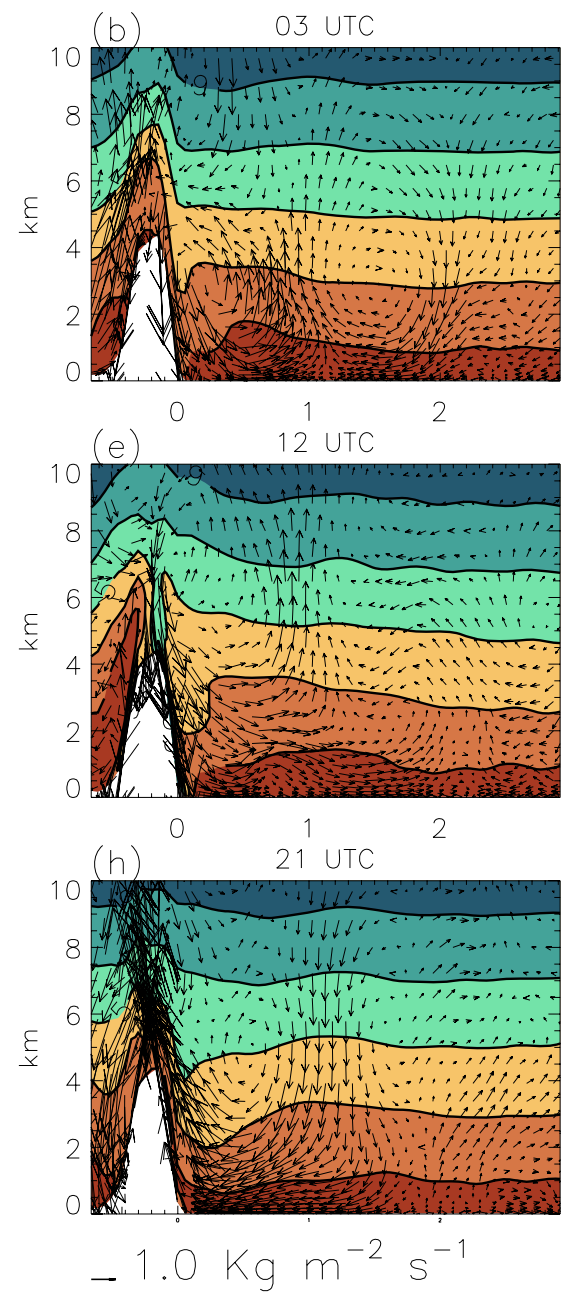
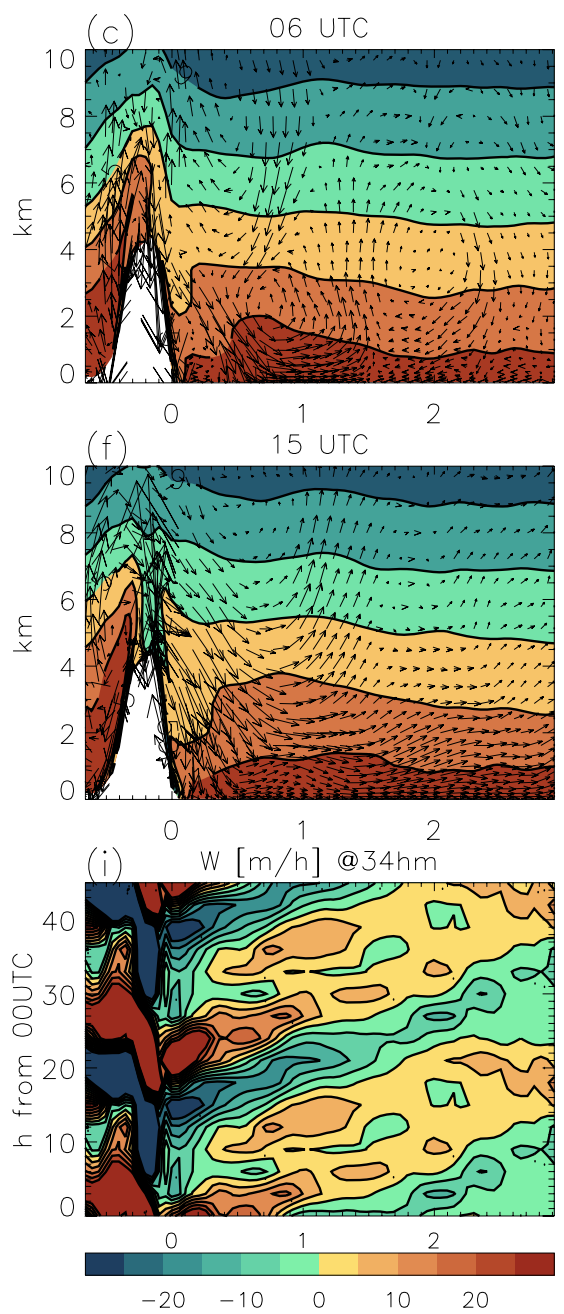

Fig. 6. (a-h) Snapshots of the mean circulation through a daily cycle along a great circle at a right angle to the South-Peruvian orographic slope and intersecting the coastline at $75.6^{\circ} \mathrm{W}, 23.3^{\circ} \mathrm{S}$. The long-term mean circulation has been removed and average anomalies for the time of the day are shown as indicated at the top of each panel in hours UTC. The abscissae indicate offshore distances in Mm, and the ordinates vertical heights in $\mathrm{km}$. The arrows represent two components of the flow, the offshore and the vertical mass fluxes (scale arrow at the bottom of panel $\mathbf{h}$ ). The colour-filled contour lines depict the nominal displacement (exaggerated 10-fold) of constant-height surfaces at 00 UTC (panel a, shown at intervals of $2 \mathrm{~km}$ starting from $1 \mathrm{~km}$ ) as obtained from the time-integrated anomalies in the vertical velocity. (i) Hovmueller diagram for the vertical velocity anomalies, in metres per hour, as a function of time (increasing upwards) and offshore distance for a twice repeated daily cycle.

variations of the surface winds. These processes are likely to exert a significant control on the diurnal cycle in the area most intensively observed during VOCALS-REx (Zuidema et al., 2009). More generally, they indicate that the interplay between local, meso-scale, and large-scale processes can be very important.

The diurnal cycle over the SEP thus is forced by a combination of local irradiation, and gravity waves emanating from the predominantly dry regional mountain breeze systems. Differential heating of the slopes with different exposure to solar irradiation is undoubtedly a significant factor in determining the overall pattern and timing of the diurnal cycle in the SEP (Munoz, 2008). A contribution from the moist convective activity over the eastern and northern side of the Andes, and possibly further afield, is also likely. Isolating the sources of forcing of the diurnal cycle in the SEP, and disentangling their effect, is the objective of current investigation.

\section{Temporal evolution of the large-scale circulation}

As VOCALS-REx progressed in Spring 2008, significant changes in the mean field conditions and in their day-to-day variability were encountered. Most marked was the change in character of the flow and its variability from the end of October onwards, as shown and discussed in Sect. 7. Part of this evolution is attributable to the evolution of the large-scale 

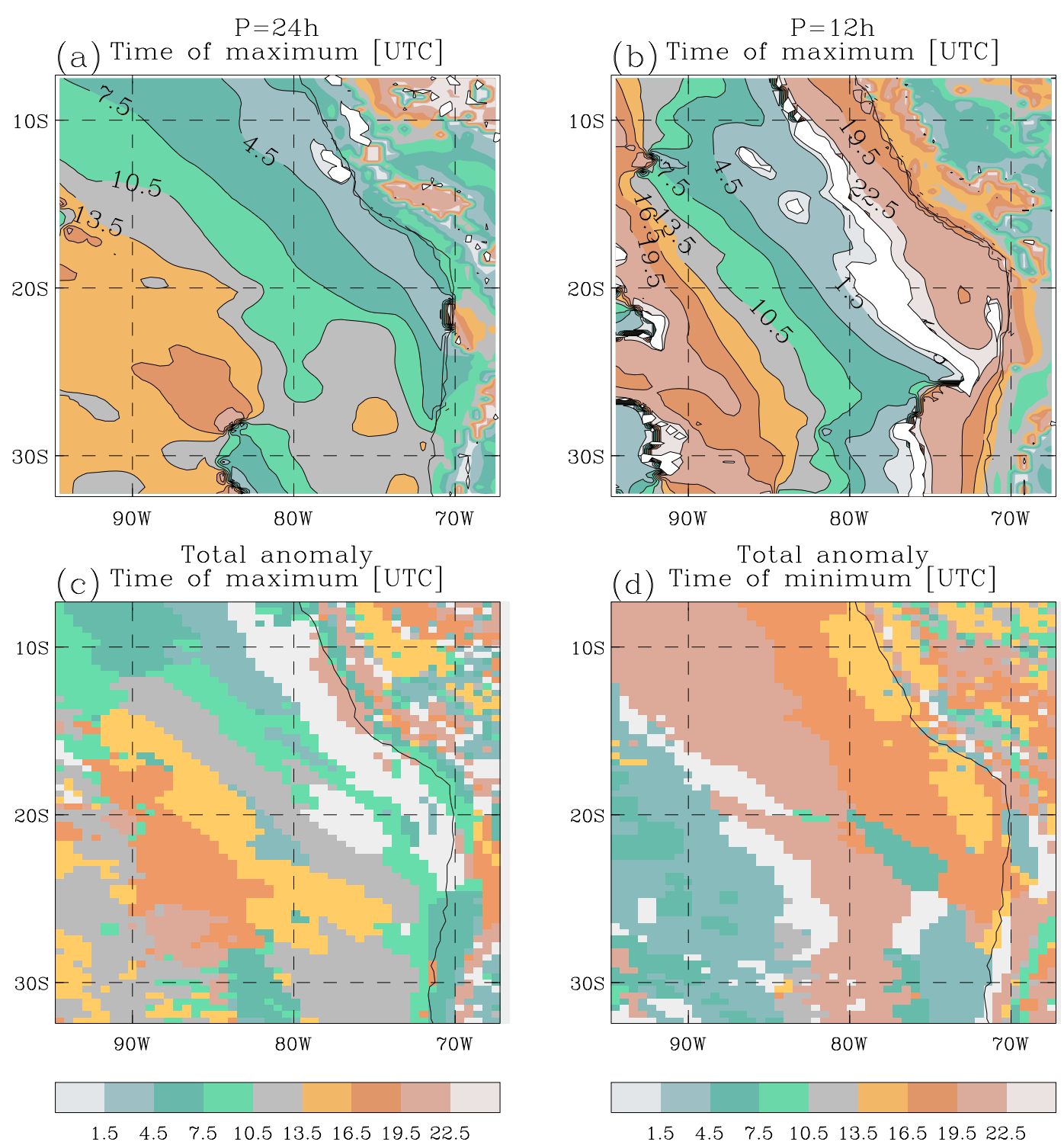

Fig. 7. (a) and (b) Negative phase offset, in hours, of the cosine component of 24-h (left) and 12-h (right) period of the vertical velocity anomalies at $5800 \mathrm{~m}$ for the mean diurnal cycle in the SEP. (c) and (d) Approximate time of maximum (positive, left) and time of minimum (negative, right) in the $5800 \mathrm{~m}$ vertical wind anomalies. UKMO operational analysis (00:00 h UTC) and forecast (03:00 h-21:00 h UTC) data at three-hourly intervals.

circulation with the march of the season. We focus here on changes in the subtropical jet stream and on diabatically forced streamfunction anomalies that interested the SEP.

The storm-track is markedly different between three meteorologically distinct periods (discussed in Sect. 7.2) that characterised VOCALS-REx (Fig. 8). In October, upstream of the south-American coast the storm track has a broader meridional spread, with activity at sub-tropical latitudes north of $30^{\circ}$. A strong interaction with the continental topography is suggested by the maxima on the two sides of it. In early November, by contrast, storms develop in a narrow, sub-polar zonal band, with little evidence of affecting the tropical inversion in the way indicated in Fig. 19. Later still, while baroclinic activity returns north, it appears weak near the South-American coast. This period in the second half of November is also characterised by steady north-westerly mid-tropospheric flow, accompanied by reduced subsidence (Fig. 20c).

The period with reduced synoptic-scale variability in the first part of November also tends to show lower inversion heights and increased cloud cover. Based on point observations over F. Felix island $\left(80^{\circ} \mathrm{W}, 26.5^{\circ} \mathrm{S}\right)$, Painemal et al. (2010) also observe a higher incidence of a deep MBL, along with its greater variability, in the presence of midlatitude synoptic forcing, consistently with Fig. 18. This may be interpreted in terms of the effect that the secondary, 

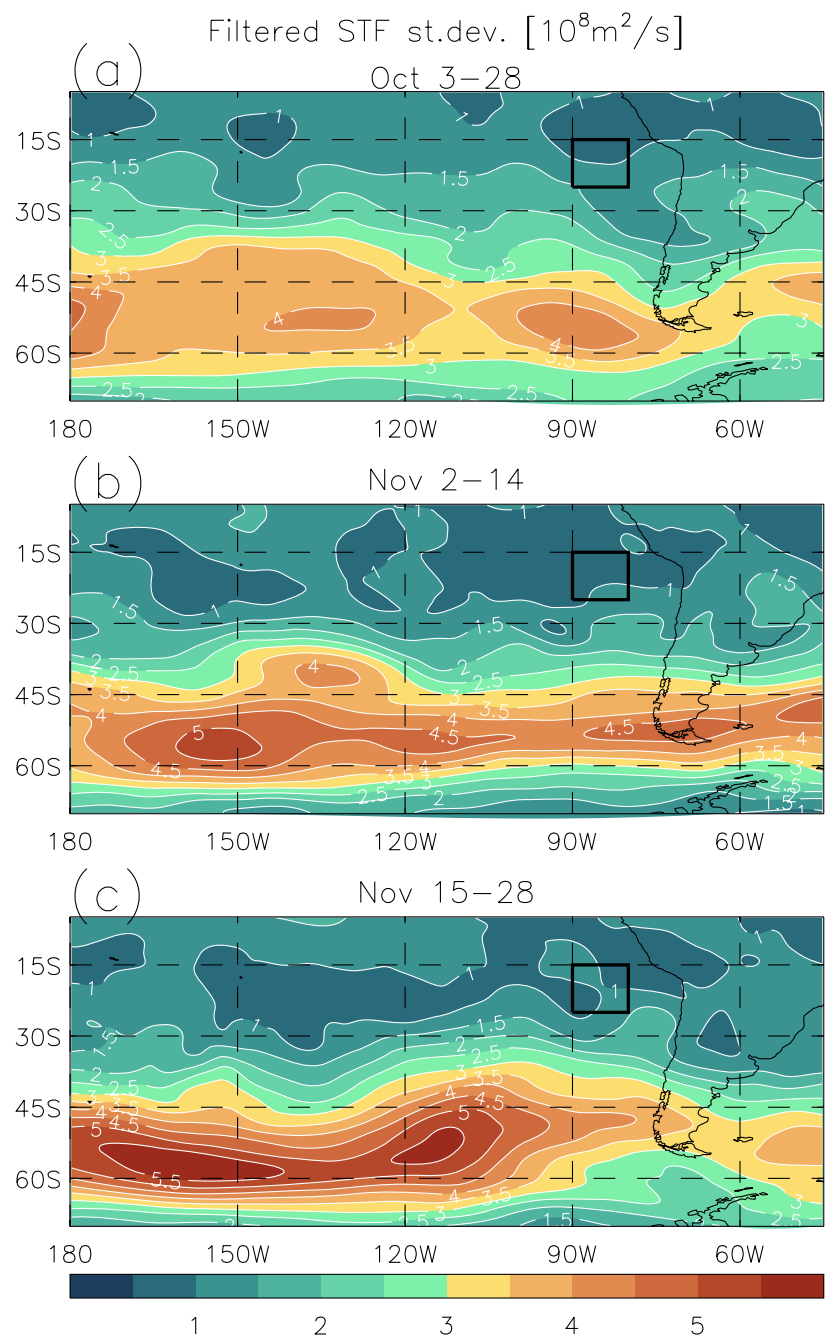

Fig. 8. (a), (b), and (c) 6-day running standard deviation of the 1-to-6-day high-pass filtered $50 \mathrm{hm}$ streamfunction for three meteorologically distinct periods during the VOCALS-REx campaign. Data from the UKMO operational analyses.

ascending circulation associated with the equatorward flank of a storm track can have on the Sc inversion.

The changes in the storm track during the two months of the campaign within the SEP sector reflect, at least in part, the normal seasonal evolution of the large-scale circulation. In general, the spring season is characterised by a large shift in the mid-latitude jet. In the south Pacific, the sub-tropical branch weakens considerably, and a characteristic split-jet structure emerges.

This evolution is represented in Fig. 9 for OctoberNovember 2008. The subtropical jet, which is prominent during the first half of October, shows a split structure with a distinct sub-polar branch in the second half of the month, and is largely reduced to the Indo-Australian sector in November. This evolution may explain some of the changes observed in baroclinic activity investing the VOCALS-REx region. In addition, the subtropical jet initially acts as a wave-guide for any disturbances generated upstream, resulting in very weak persistent wave-like anomaly patterns, hardly escaping tropical latitudes. Starting from the beginning of November, with the break-down of the subtropical jet, and the increased prevalence of (weak) westerlies near the tropical areas of deep convection, a slowly evolving Rossby wave pattern begins to appear, which is well established in the last period of the campaign, with increased cyclonic circulation over the SEP, coincident with northerly flow, and dynamically induced lofting from vorticity conservation. The occurrence of this pattern coincides with the increased day-time cloud break-up which characterised the latter part of the campaign.

In parallel with this evolution poleward of the VOCALSREx area, beginning from the last days of October and into the first half of November moist convection over tropical South America becomes active, establishing at least temporarily a characteristic (e.g. Fig. 2) warm anticyclone over the Bolivian Altiplano (Fig. 9c), as might be generally expected from the progression of the season. This activity is associated with a particularly warm upper troposphere and increased descent above the VOCALS-REx area during that period. We will see in the next Sect. 6 however that tropical convection over South America was, in general, relatively weak during Spring 2008.

\section{Anomalies and teleconnections}

For the duration of the campaign, large-scale SSTs anomalies in the sub-equatorial Pacific indicate a prevalence of weak La-Niña like conditions (Fig. 10). In the eastern Pacific, however, SSTs are close to their climatological values. Insitu and satellite SST products indicate that anomalies in the SEP for October and November 2008 are less than $0.5^{\circ} \mathrm{C}$ in magnitude. These values are comparable with the discrepancies among such products, and therefore not significant. Among the data-sets used in Fig. 10, the NOAA OI most closely matches the in-situ data collected by the R. H. Brown near $20^{\circ} \mathrm{S}$ in November. The UKMO OSTIA product compares even better, but it covers an insufficient temporal span for an estimate of the interannual anomaly. Averages for the single months of October and November do not show additional significant features.

Consistently with cool central-Pacific conditions, and the corresponding expansion of the Hadley cell, the angular momentum of the atmosphere is reduced compared to its climatological values (not shown). This is accompanied by an increased atmospheric sub-polar meridional temperature gradient, reinforcing the sub-polar jets, especially in October (Fig. 11). The large-scale evolution described in the previous section might therefore not be untypical for this season in the southern hemisphere. However, due to the sea-level pressure anomalies, the weakening of the subtropical surface 

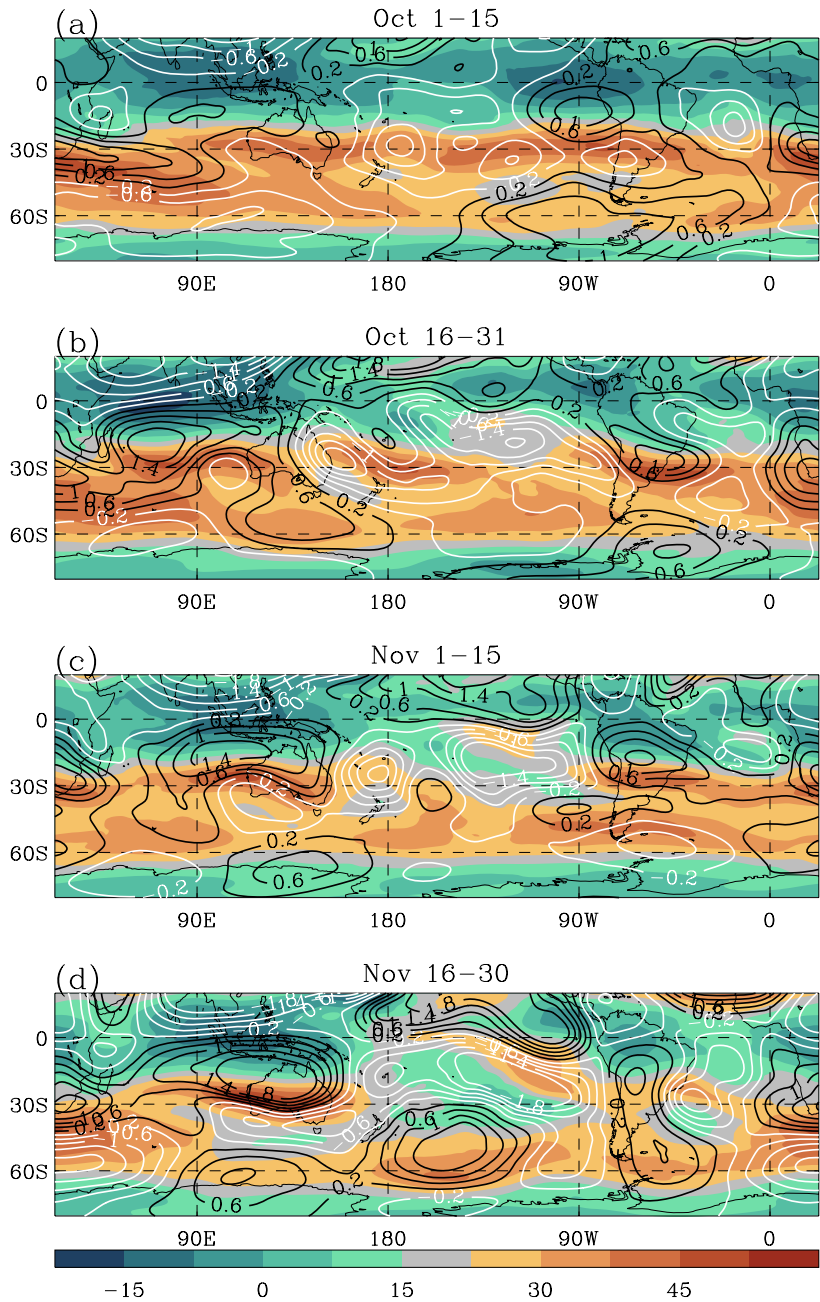

Fig. 9. Zonal wind at $200 \mathrm{hPa}$, in units of $\mathrm{ms}^{-1}$, for four fortnight periods in October and November 2008 (colour coding, scale at the bottom). Contour lines show the zonally asymmetric component of the $200 \mathrm{hPa}$ streamfunction. Contour interval is $4 \times 10^{6} \mathrm{~m}^{2} \mathrm{~s}^{-1}$; white contours indicate negative values (clockwise, or cyclonic, circulation in the Southern Hemisphere), and black positive values (anticlockwise, or anticyclonic, circulation). Data from UKMO operational analyses.

high between October and November is stronger than usual. Conversely, at the sub-tropical latitudes of VOCALS-REx (north of $45^{\circ} \mathrm{S}$ ), synoptic variability, as estimated from the 7-day high-pass filtered variance of the $500 \mathrm{hPa}$ streamfunction in the ERA-Interim reanalysis, is below the climatological average for the period 1989-2008, especially in October (not shown). The anomaly resembles that of early November compared to October 2008 (Fig. 8, panels (b) and (a), respectively). The implication is that the strong baroclinic activity observed in October to invest the VOCALS-REx area was not by any means exceptional, and the transition to reduced mid-tropospheric synoptic variability probably less marked than normal.
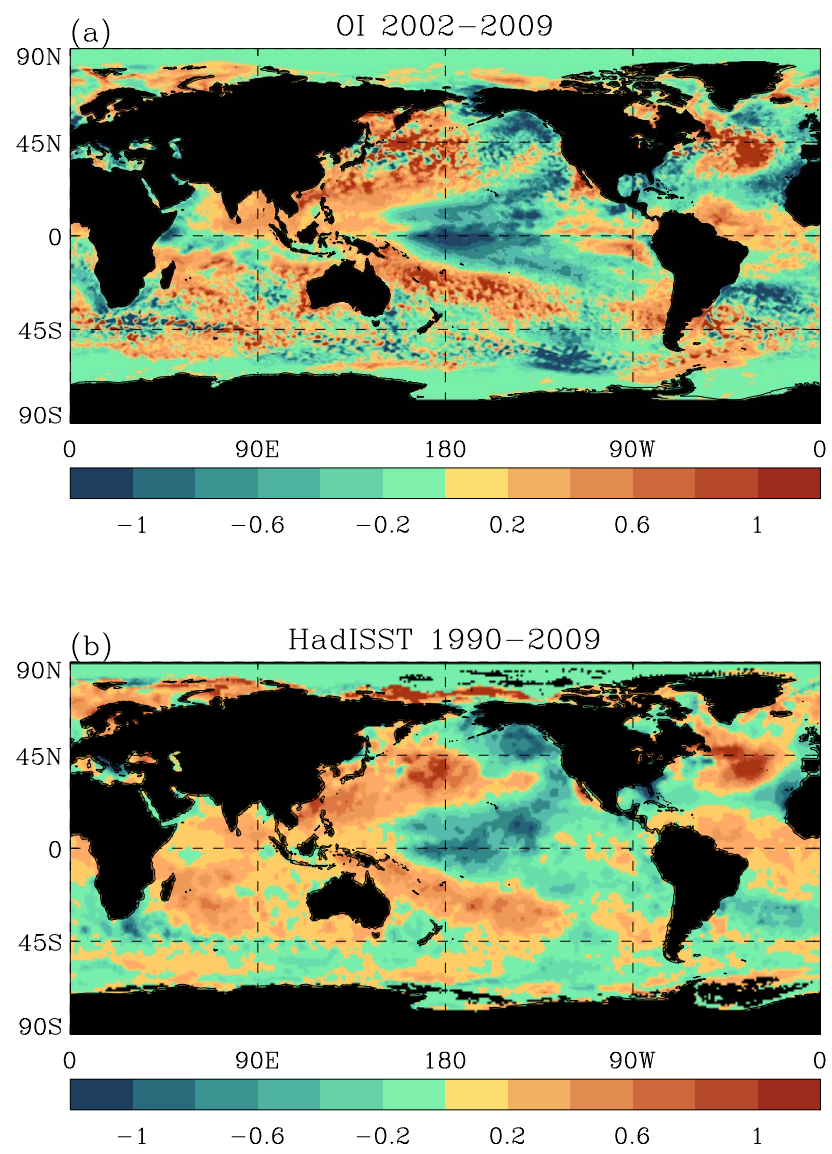

Fig. 10. SST anomalies as diagnosed for the period OctoberNovember 2008 as estimated from satellite-derived (NOAA OI v2; panel a) and from in-situ (HadISST; panel b) data products. The reference periods used for the climatologies are given in the title of each panel.

Towards the end of the previous section we noted that the upper-level circulation in this period appears to have been mainly remotely forced. Consideration of the interannual anomalies tends to support this hypothesis. Figure 12 shows the interannual anomalies, for the same four periods of Fig. 9, of TOA OLR (green contour lines), velocity potential (colour coding), and eddy streamfunction (white contour lines).

Although the weak warm SST anomalies in the Atlantic might be expected to act to sustain convective activity over the Amazon basin, this was subdued compared to the climatology (cf. Fig. 12). Increased, i.e. near-climatological activity between the end of October and the first half of November gave way to a further dry spell, with rainfall moving north of the Equator at the end of the VOCALS-REx period.

Prominent anomalies of the circulation in the westernPacific sector are visible in Fig. 12. They correspond to a active phase of the Madden-Julian Oscillation (MJO; Madden and Julian, 1972), with intense convective activity moving from the eastern Indian ocean to the west Pacific between late October and early November. The associated 

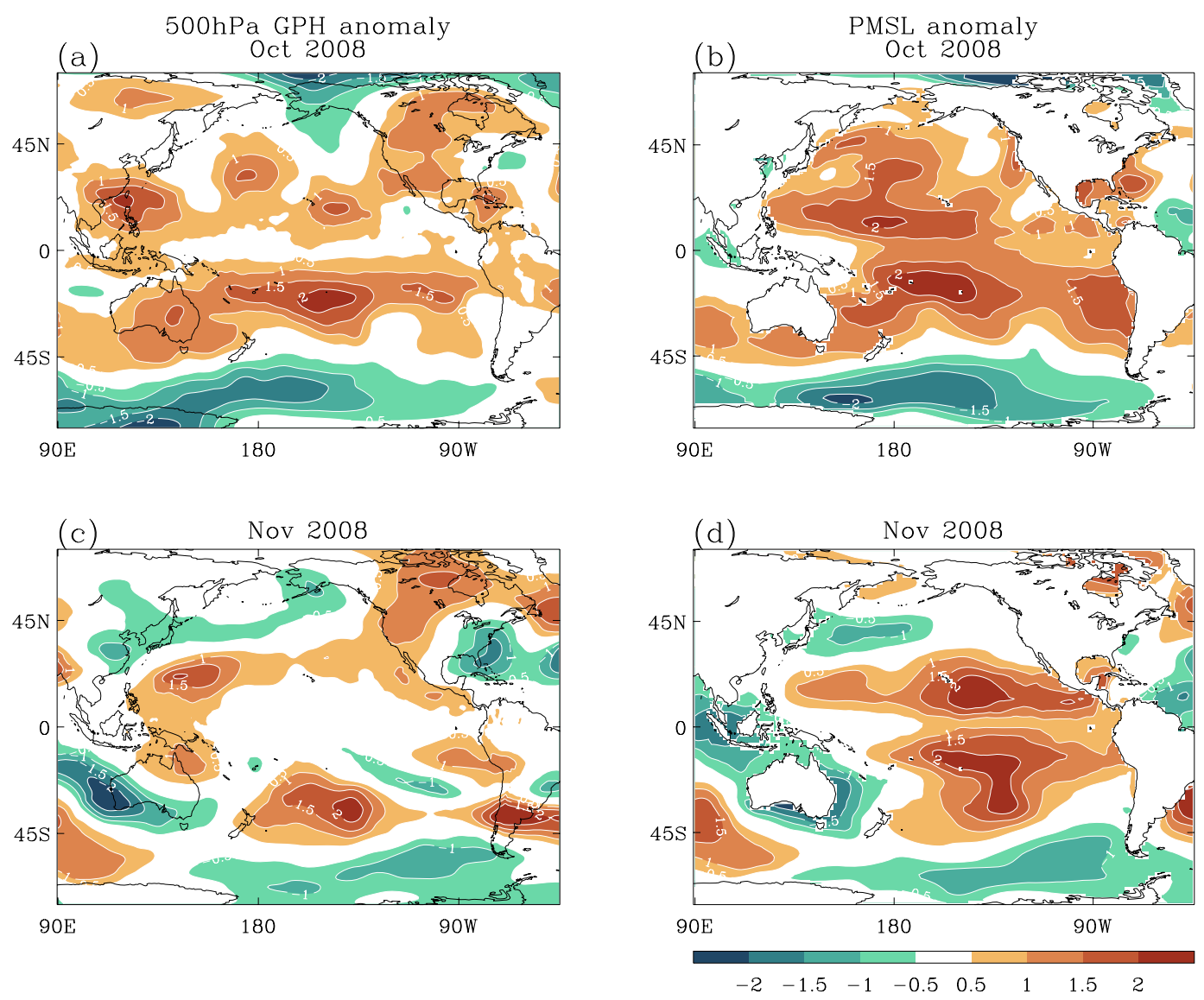

Fig. 11. Interannual anomalies for the months of October and November 2008. Panels (a) and (c) show the geopotential height at $500 \mathrm{hPa}$, panels (b) and (d) the anomalies in sea-level pressure. Reference climatology is for the period 1989-2008. Data from the ERA-Interim reanalysis (Simmons et al., 2006).

velocity-potential and streamfunction anomalies are consistent with a quasi-stationary Rossby wave-train emanating from the region of enhanced convection west of the dateline, which generate a Pacific-South-American (PSA) pattern, with a cyclonic centre in the SEP, in late November. A connection of this type between convective activity in the West Pacific and the occurrence of a PSA pattern of the sign given in Fig. 12 has been shown in the climatological context by Mo and Higgins (1998). We will see below that the persistent cyclonic anomaly over the SEP had significant consequences for the regional meteorology observed in VOCALSREx.

\section{Characterisation of the meteorology during VOCALS-REx}

\subsection{General}

Figure 13 depicts the mean surface and MBL conditions encountered during the VOCALS-REx observations campaign between 1 October and 2 December 2008.
As is typical for austral spring, sea surface temperatures (SSTs) along the coast were cold offshore of the strongest upwelling zones. These are located both to the south and to the north of the Arica bight, where SSTs had a local maximum (Fig. 13b). Away from the coast, the SST gradient is to the west and northwest.

Within the region of observations, surface winds were typically south-southeasterly, with a direction ranging from $177^{\circ}$ at $20^{\circ} \mathrm{S}, 71^{\circ} \mathrm{W}$ to $125^{\circ}$ at $20^{\circ} \mathrm{S}, 85^{\circ} \mathrm{W}$ (Fig. 13a). West of $75^{\circ} \mathrm{W}$, directionality was very steady, with a daily standard deviation of less than $10^{\circ}$; this figure rises to about $30^{\circ}$ close to the coast.

The general alignment of the surface winds with the SST gradient implies cold advection in the MBL. This is capped by a strong inversion located at a pressure ranging from $900 \mathrm{hPa}$ near the coast, to about $800 \mathrm{hPa}$ on the open sea in the time average. Away from the coast, significant temporal variations of the inversion height occur, mainly on synoptic time-scales, with heights ranging between $900 \mathrm{hPa}$ and $700 \mathrm{hPa}$ at $90^{\circ} \mathrm{W}$, and between $930 \mathrm{hPa}$ and $850 \mathrm{hPa}$ at $75^{\circ} \mathrm{W}$. The temperature jump across this inversion is in the range $10-15^{\circ} \mathrm{C}$, and $\mathrm{RH}$ typically drops from saturation 

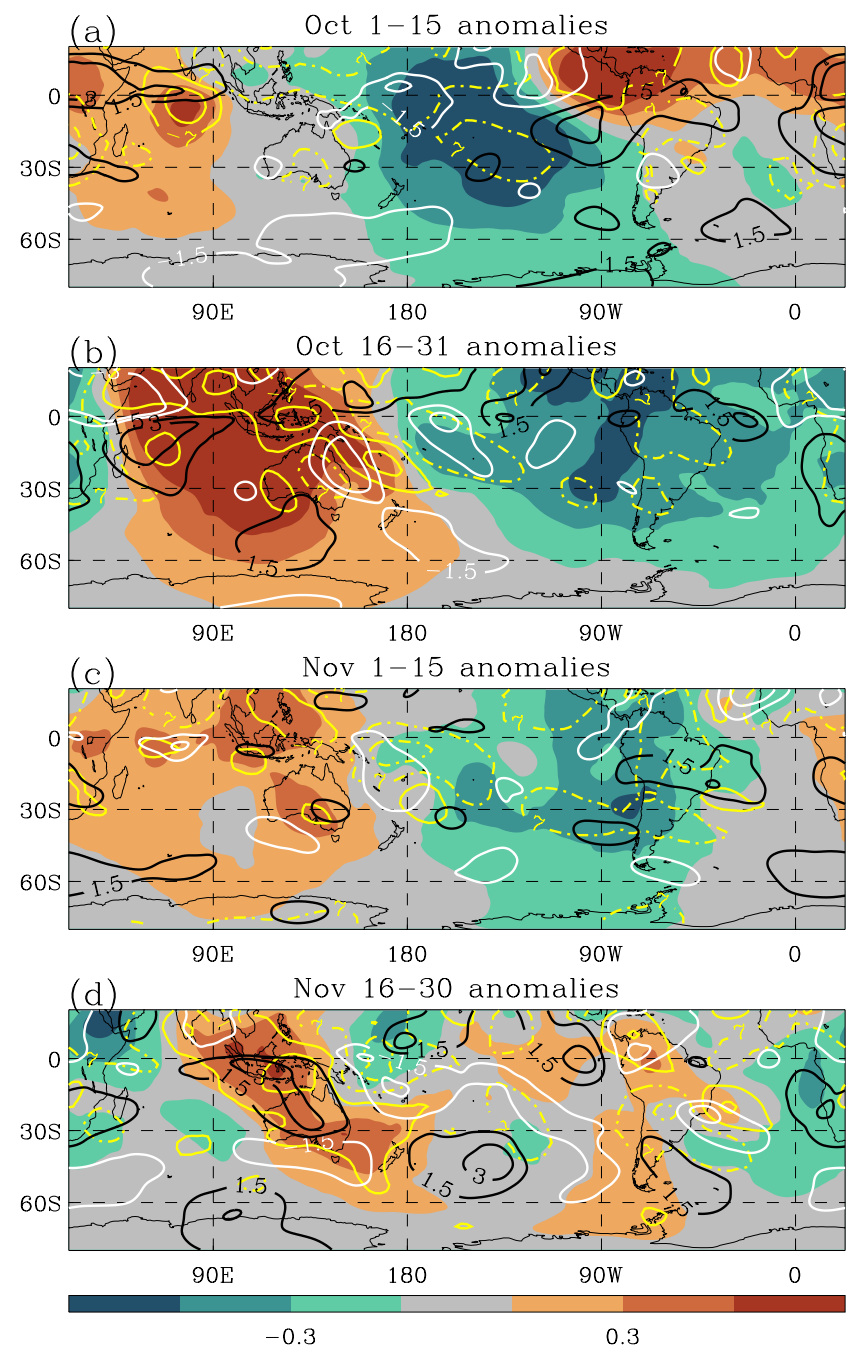

Fig. 12. Velocity potential and streamfunction anomalies at $200 \mathrm{hPa}$ (colour-coding and black and white contours, respectively) from ERA-Interim, and OLR anomalies (yellow contours) from the NCEP CDC interpolated OLR data-set, for the four periods corresponding to the four panels in Fig. 9. The units for the velocity potential are $10^{7} \mathrm{~m}^{2} \mathrm{~s}^{-1}$, and the contour interval is $2 \times 10^{6} \mathrm{~m}^{2} \mathrm{~s}^{-1}$. The streamfunction anomalies are given in units of the local standard deviation from the 20-yr monthly-mean climatology. The contour interval is 1.5 , with the zero-line omitted, and contours are black for positive, and white for negative values. For OLR, the contour interval is $7 \mathrm{~W} \mathrm{~m}^{-2}$, and contour lines are broken for positive values, and solid for negative values.

or near-saturation to less than $10 \%$, although higher values have also been observed. A thermal wind is associated with the mean gradient in inversion height. Near $20^{\circ} \mathrm{S}$, the latter is largely aligned with the wind itself, resulting in little directional change (a slight backing), and the wind remains eastward near the coast and north-eastward offshore. An additional thermal wind component above this level is associated with the predominantly meridional mean temperature gradi-
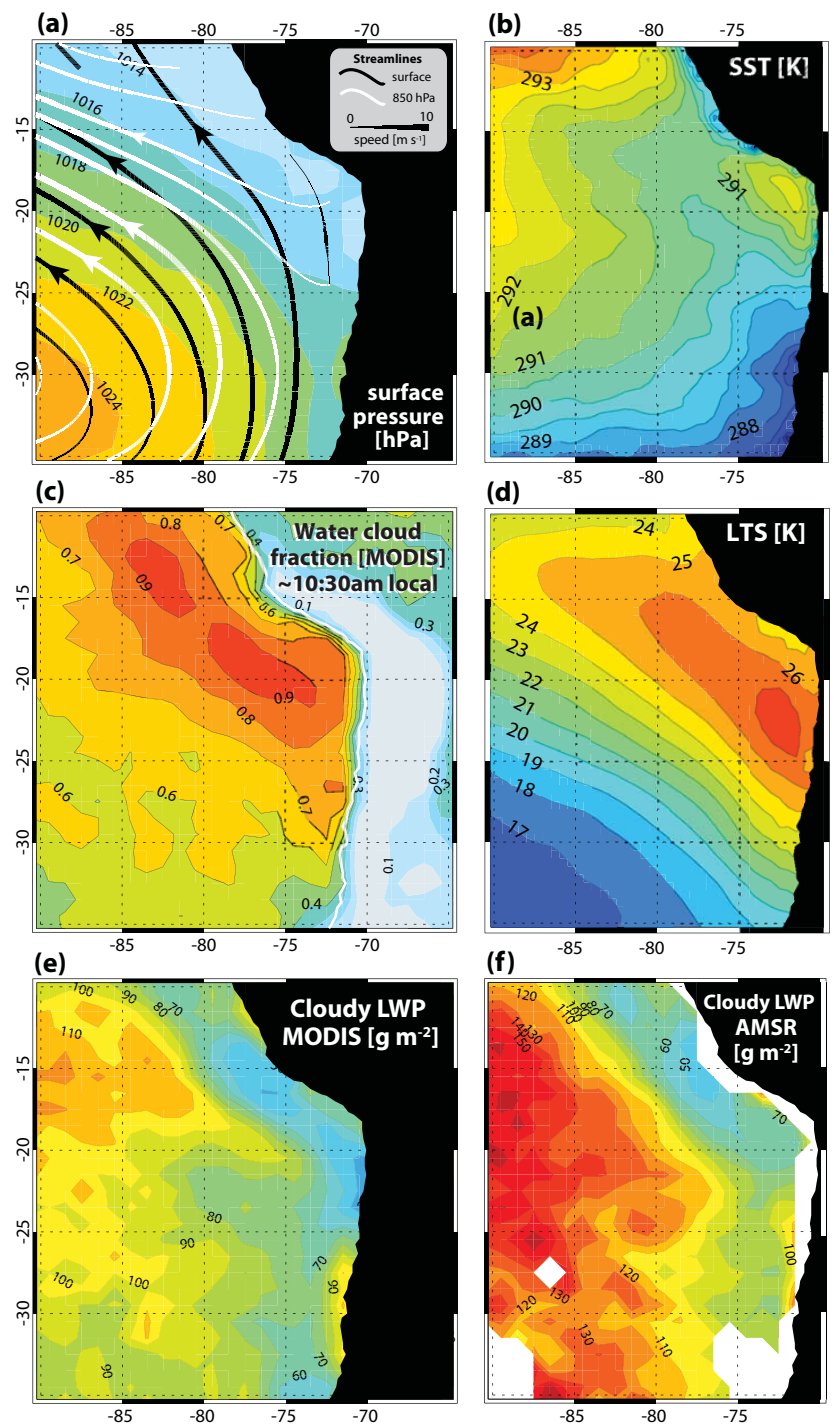

Fig. 13. October-November mean values of (a) sea level pressure (colour contours) and flow streamlines at the surface (black) and at $850 \mathrm{hPa}$ (white); (b) sea-surface temperature from the NOAA Optimal Interpolation analysis; (c) fractional cover of water clouds for October-November 2008 at 10:30 a.m. local time as determined by MODIS; (d) lower tropospheric stability (LTS, difference between potential temperature at $700 \mathrm{hPa}$ and surface) from the ECMWF operational analyses; (e) mean LWP for cloudy pixels from MODIS; (f) mean LWP for cloudy pixels from AMSR (AMSR LWP/MODIS warm cloud fraction). In (e) and (f), we use the area mean diurnal mean LWP from AMSR (mean of 01:30 and 13:30 LT) divided by the mean warm cloud cover from MODIS, to provide an estimate of the cloudy sky LWP.

ent in the free troposphere. The mean direction changes to between westerly and southerly at $700 \mathrm{hPa}$, with a strong reduction in mean wind-speed. However, wind directional variability also becomes markedly larger $\left(45^{\circ}-60^{\circ}\right.$ in daily standard deviation), increasingly so away from the coast. 
The mean liquid-water cloud cover, obtained from MODIS Terra satellite at 10:30 LT, is shown in Fig. 13c. It reaches its maximum within a belt at a distance of $500 \mathrm{~km}$ from, and roughly parallel to, the Peruvian coast, with mean values exceeding $90 \%$. This region is situated a few hundred $\mathrm{km}$ downwind of the maximum in lower tropospheric stability (LTS, Fig. 13d), which is defined the difference between the potential temperature at $700 \mathrm{hPa}$ and the surface. Over most of the region sampled in VOCALS-REx the mean warmcloud cover exceeded $70 \%$, except very close to the coast where topographic irregularities and the advection of drier air masses are conducive to local clearings.

Figure $13 \mathrm{e}$ and $\mathrm{f}$ also show the mean liquid water path (LWP), as determined for cloudy pixels using the visible/near-IR retrievals from MODIS (panel e) and from the passive microwave Advanced Microwave Scanning Radiometer (AMSR; panel f). The two estimates agree very well within about $500 \mathrm{~km}$ of the coast, where the potential contamination of the AMSR estimate by drizzle is limited (as evidenced from VOCALS-REx aircraft observations, Bretherton et al., 2010). Within this region, typical cloud LWP values were $70 \mathrm{~g} \mathrm{~m}^{-2}$ or less.

Liquid water paths increase westwards, in agreement with in-situ observations (Bretherton et al., 2010). Still further west, the microwave-derived LWP estimates from AMSR increasingly exceed those from MODIS, which is indicative of increasing amounts of drizzle (see e.g. Shao and Liu, 2004) formed in the thicker clouds of the deeper maritime MBL (Wyant et al., 2010; Zuidema et al., 2009).

While the mean flow illustrated in the previous section is somewhat representative of the observed day-to-day conditions in the MBL, in the FT variability on synoptic timescales was very substantial.

The cloud-cover was observed to respond to the synopticscale variability of the circulation above the inversion to a degree such that the 48-h operational forecasts of synoptic conditions could be usefully employed to estimate the expected changes in observable field conditions during the VOCALSREx campaign. The forecast cloud fields themselves provided a good guidance for the expected cloud cover.

In general, the main source of synoptic variability in the VOCALS-REx region was baroclinic activity in the jetstream system, causing ridging and troughing in the FT which tended to be amplified by orographic effects near the Andes. This was associated with anomalous advection of air-masses from different latitudes or altitudes, following the ridging of the isoentropes.

When the disturbance was sufficiently strong, it developed into a coastally-intensified cyclone (Garreaud et al., 2002; Garreaud and Rutllant, 2003), most clearly seen in the lower FT at about $700 \mathrm{hPa}$. In a few instances (e.g. 19-20 November), such coastal lows locally reversed the zonal component of the flow across the Andes to easterly, causing the advection of land air-masses into the maritime SEP area.
While anomalous cold or warm advection in the FT associated with these systems was common, occasionally regions at the low-latitudes of the VOCALS-REx area were directly interested by trailing cold fronts, with an ensuing sharp drop in FT temperatures. Such events appear to be more frequent on the eastern slopes in the lee of the Andes, but on 23-24 October such a cold front extended throughout the troposphere just above the MBL along $20^{\circ} \mathrm{S}$.

In addition, changes in the extent of the mid-tropospheric high, associated with changes in heating either from the elevated terrain of the Bolivian altiplano or from deep convection on the western and southern Amazon basin, caused modulations of the sub-tropical jet-stream on its equatorward flank which sometimes were associated with the formation of low-latitude cyclones.

\subsection{The day-to-day synoptic conditions over the SEP Depth of the MBL and variability in oceanic cloud during October and November 2008}

The general meteorological conditions for the period of interest are shown in Fig. 14c. For each day, we show the cloud field using the difference $\Delta T$ between the SST (as given by the daily-mean OSTIA product; Stark et al. (2007) and the GOES-10 Channel $5(12 \mu \mathrm{m})$ brightness temperature; the latter has been interpolated onto the 0.05 degree-square OSTIA grid, conserving areal averages. Since few low cloud tops occur below $600 \mathrm{~m}$ in the region (e.g. Zuidema et al., 2009), all values of $\Delta T<6 \mathrm{~K}$ are left in black to indicate virtually cloud-free regions, while all values above $35 \mathrm{~K}$ are considered to originate from high clouds and are marked in white. The lower threshold is still somewhat problematic because differences less than $8 \mathrm{~K}$ can still indicate either low, continuous cloud cover, or fields of broken cumulus with relatively high cloud tops. Comparison with GOES-10 daytime images in the visual band generally supports the choice made, and broken cumulus fields tend to be infrequent in the VOCALS-REx study area. We show this temperature difference field twice-daily: (a) during early morning before sunrise (where available, 10:28 UTC, i.e. 05:08 LT at $80^{\circ} \mathrm{W}$ ), when the cloud cover is most extensive, and (b) in the afternoon (19:45 UTC, or 14:25 LT at $80^{\circ} \mathrm{W}$ ) when the clouds are near their thinnest (Wood et al., 2002), and on many days the stratocumulus deck partially breaks up (Rozendaal et al., 1995; Bretherton et al., 2004; Abel et al., 2010). 
Superimposed on the night time $\Delta T$ fields in Fig. $14 \mathrm{c}$ are sea-level pressure contours for the previous 00:00 UTC, and on the day time field contours of the zonally asymmetric part of the $500 \mathrm{hPa}$ geopotential height field are drawn. The final two panels in Fig. 14c show the average night-time and daytime cloud-top temperatures at each location whenever low cloud is diagnosed (i.e. whenever $\Delta T$ is within the stated thresholds of $6 \mathrm{~K}$ and $35 \mathrm{~K}$ ), with contours for mean pressure and $500 \mathrm{hPa}$ height overlaid as before.

We discuss here two important aspects of the variations in the cloud field in the VOCALS-REx region. Day-to-day variations in the cloud fields are comparable to diurnal variations, and in some cases dominate. These synoptic changes occur in coincidence with changes in sea-level pressure and the passage of mid-tropospheric synoptic-scale disturbances. In particular, there is a strong association between low $500 \mathrm{hPa}$ heights and cyclonic flow at $500 \mathrm{hPa}$, and large-scale clearing and breaks in the cloud cover, particular towards the south of the VOCALS-REx study region. This is particularly evident when synoptic systems approach the South American coast (e.g. 1-3 October, 10-13 October, 20-25 October, 1215 November, and after 24 November). Equally remarkable are the intervening episodes of synoptic ridging, particularly during October, which coincide with increased Sc cloud-cover.

Superimposed on this distinctly synoptic variability, circulation-related anomalies can be observed at both smaller and larger spatial and temporal scales. Near land, enhanced orographic subsidence associated with synoptic-scale ridging is responsible for sudden, strong coastal clearings.

This is accompanied by a localised reduction in sea-level pressure and formation of a coastal low (CL), as discussed in Garreaud et al. (2002). The coastal clearings typically persist for up to 3 days after the initial mid-tropospheric ridging, and they tend to be located in the southern part of the domain of interest here, where the coastal jet is strongest, consistent with the dynamics discussed by Munoz and Garreaud (2005). Such "canonical" CLs are seen to occur during 4-5 October, 17-18 October, and 10-11 November.

The association between mid-tropospheric ridging and sea-level troughing along the coast distinguishes CLs from mid-latitude synoptic disturbances (Garreaud et al., 2002). Nevertheless, their character is thought to depend principally on the interaction of synoptic-scale disturbances with the mountain topography, whereby changing up- and downslope flows affect the temperature and moisture stratification of the lower atmosphere near the coast, thereby affecting the pressure field. These changes also affect the cloudcover. Thus, on the one hand, CLs depend on the presence of large-scale ridging and troughing. On the other hand, height anomalies associated with synoptic disturbances generally tend to assume a baroclinic character as they interact with the orography, and to disturb the coastal cloud field in a way consistent with the associated mountain winds.
Thus, there are instances - such as 1-2 November - of weak coastal troughing and of ridging at $500 \mathrm{hPa}$ height, which are hardly accompanied by sea-level changes, but nonetheless affect the cloud field, sometimes quite significantly (e.g. 7-9 November). This particular extensive cloudclearing event is still associated with mid-latitude troughing further south (at the southern edge of the VOCALSREx study region), but also with strong warming of the midtroposphere overlying the coastal ocean north of about $25^{\circ} \mathrm{S}$, that appears to emanate from the continent to the east. This results in an enhanced mid-tropospheric meridional temperature gradient, and strong cold advection over the southern half of the domain (see Fig. 16).

The importance on the regional scale of synoptic ridging and troughing near the coast also concerns the origin of the air-masses, and their accompanying aerosol or pollutant load, that were sampled in the SEP area during the VOCALS-REx campaign. The back-trajectories arriving near the inversion along $20^{\circ} \mathrm{S}$ during VOCALS-REx, shown in Fig. 15, highlight two particular episodes during which air-masses were advected towards the Sc closer to the coast (typically, within 5 degree in longitude) from potentially polluted land areas. The first such episode occurs in 17-21 October, following an intense synoptic troughing and subsequent ridging along a NW-SE axis to the south of the VOCALS-REx area. The corresponding turning of the geopotential height contours implies advection from the central and southern portion of the Chilean land-mass. Over $20^{\circ} \mathrm{S}$, the ridging peaks on 17 October and coincides with a shallow MBL and persistent, continuous cloud cover. A weaker, but similar occurrence is seen on 16 November, also corresponding with a depressed MBL and increased cloud-cover along $20^{\circ} \mathrm{S}$. Such episodes roughly represent an intensification of the anticyclonic circulation south of the VOCALS-REx area which may be brought about by synoptic ridging.

A distinct dynamics appears to be associated with the second period when air-masses are potentially influenced by land areas, spanning roughly two weeks between the late part of October and the early part of November, but with increased relevance between 3 and 8 November. In this period, air-masses near the coast originate from the North, and appear to come in contact with Peruvian and Ecuadorean coastal land areas. From 23 October onwards increased occurrence of cirrus is observed north of $20^{\circ} \mathrm{S}$, becoming particularly marked during 3-6 November. Likewise, midtropospheric relative humidity is markedly higher than during the rest of the season. During this time, the Bolivian mid-tropospheric anticyclone appears to intensify and extend westwards over the maritime area around $15^{\circ} \mathrm{S}$. After 10 November, it becomes detached from the continent and appears to move westwards, possibly as a free planetary wave, until it is dissipated around 14 November. This evolution is accompanied by a significant warming of the freetroposphere over $20^{\circ} \mathrm{S}$. 

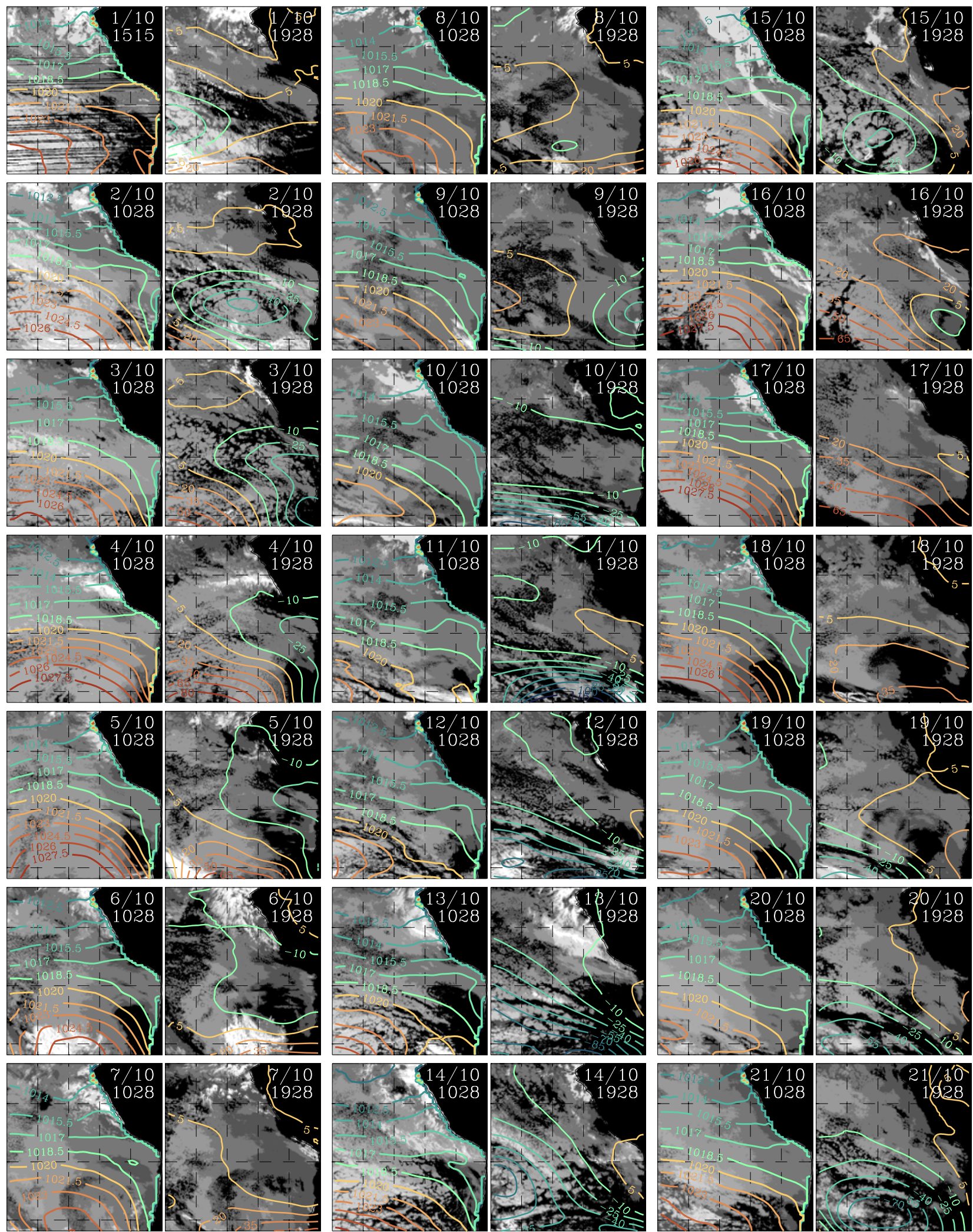

Fig. 14a. Twice-daily snapshots (UTC time as indicated) of the temperature difference $\Delta T$ between the OSTIA SSTs and the GOES Channel 5 brightness temperature. The gray colours indicate the presence of low clouds, with lighter shades indicative of higher clouds in deeper boundary layers. The contour interval for the shading is $3 \mathrm{~K}$. Values of $\Delta T$ below $6 \mathrm{~K}$ are shown in black, and values above $35 \mathrm{~K}$ are shown in white (cf. Fig.14c). See text for full details. The contour lines in the night-time panels show the sea-level pressure for the previous 00:00 UTC. The contour interval is $1.5 \mathrm{hPa}$; the $1020 \mathrm{hPa}$ line is drawn in light orange colour, and the $1018.5 \mathrm{hPa}$ line in light cyan. On the day-time panels, contours of the zonally asymmetric part of the $500 \mathrm{hPa}$ geopotential height field are drawn, for the subsequent 00:00 UTC. A contour interval of $15 \mathrm{~m}$ is used, with positive values (at and above $5 \mathrm{~m}$ ) in orange/red, and negative values (at and below $-10 \mathrm{~m}$ ) in cyan/blue. 

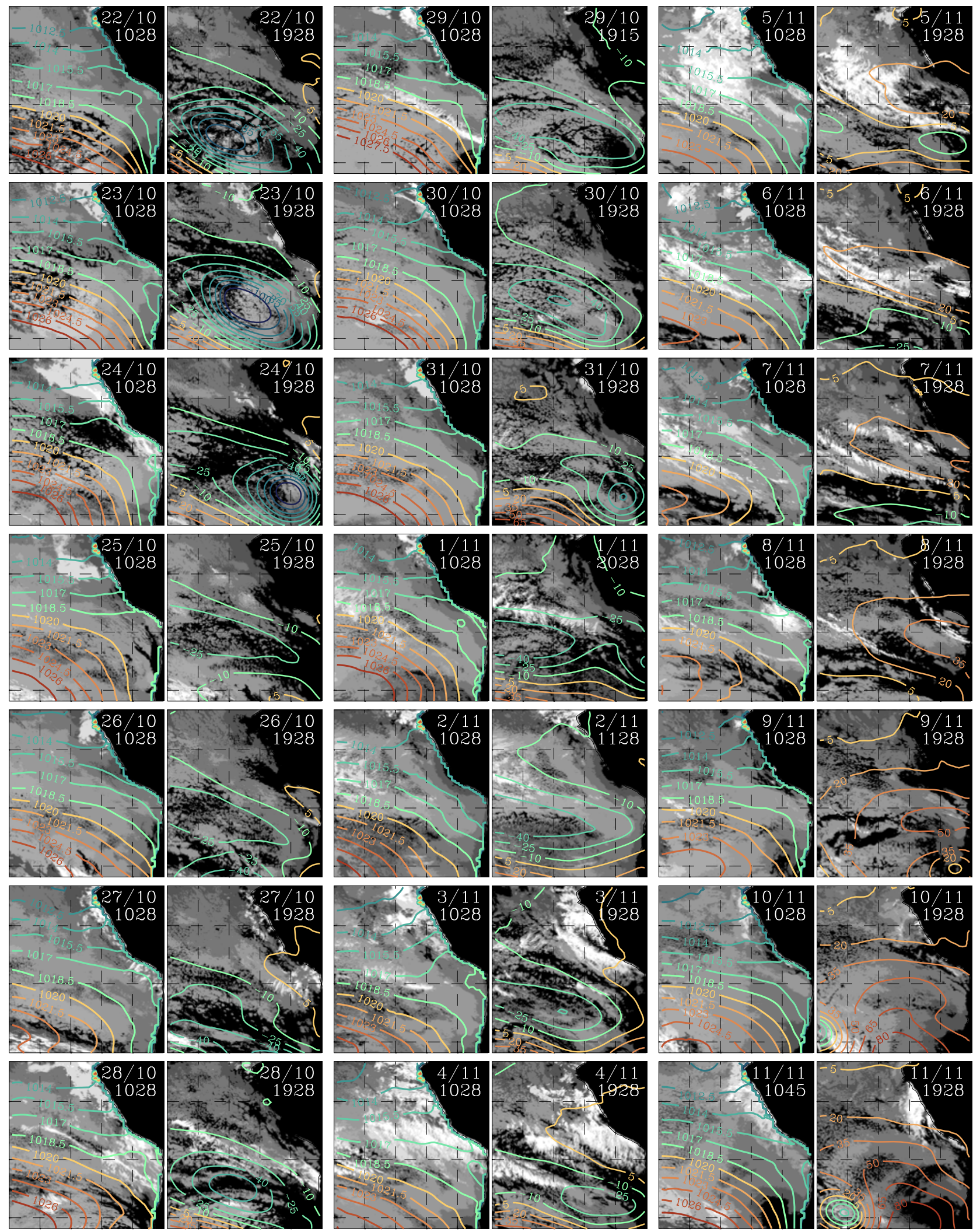

Fig. 14b. Continued. 

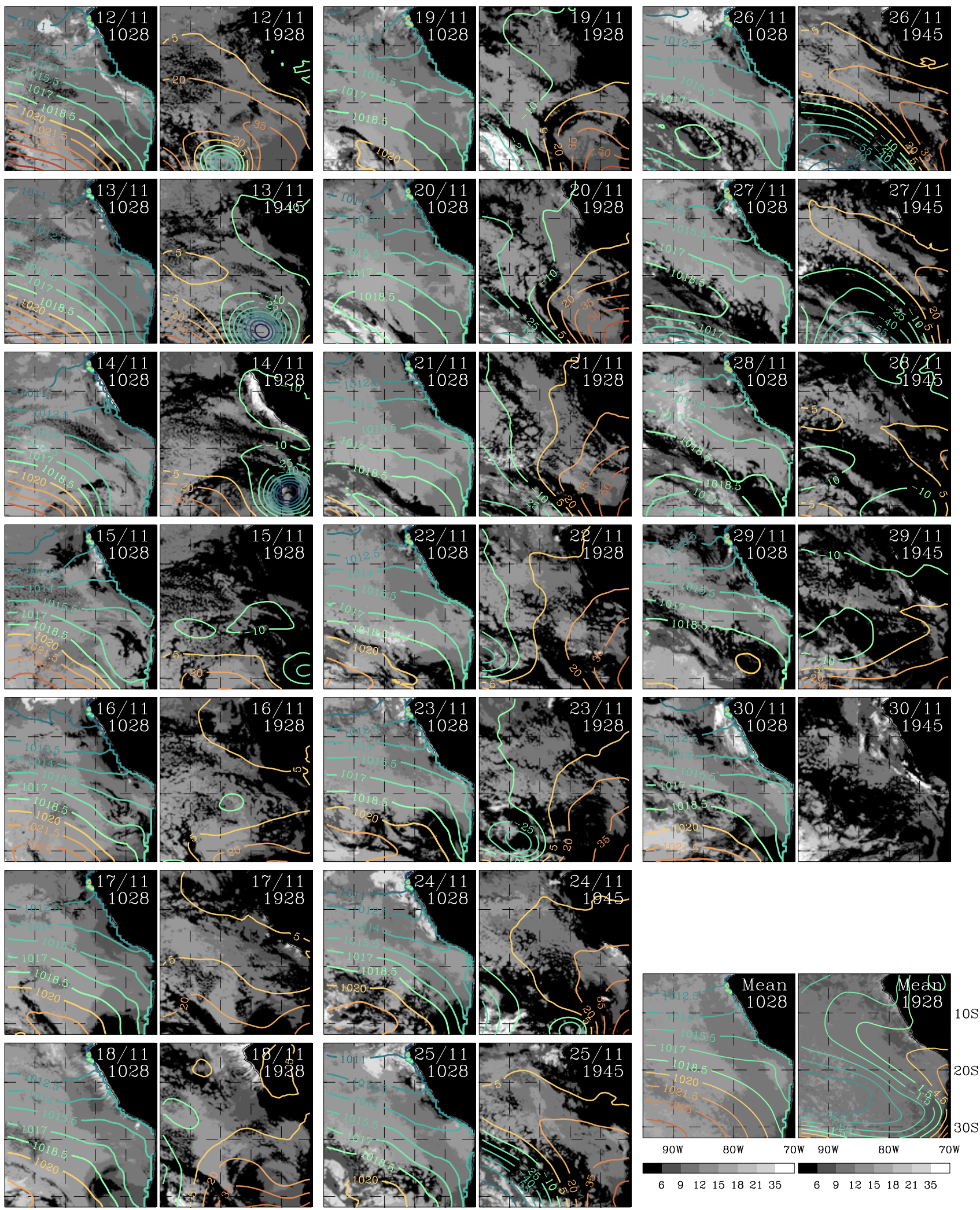

Fig. 14c. The final two panels show the October-November mean values of $\Delta T$ when cloud is present (determined as being when $3<$ $\Delta T<35 \mathrm{~K}$ ) for the morning and afternoon times, with contours of mean pressure (overlaid on morning) and $500 \mathrm{hPa}$ geopotential height (afternoon). 


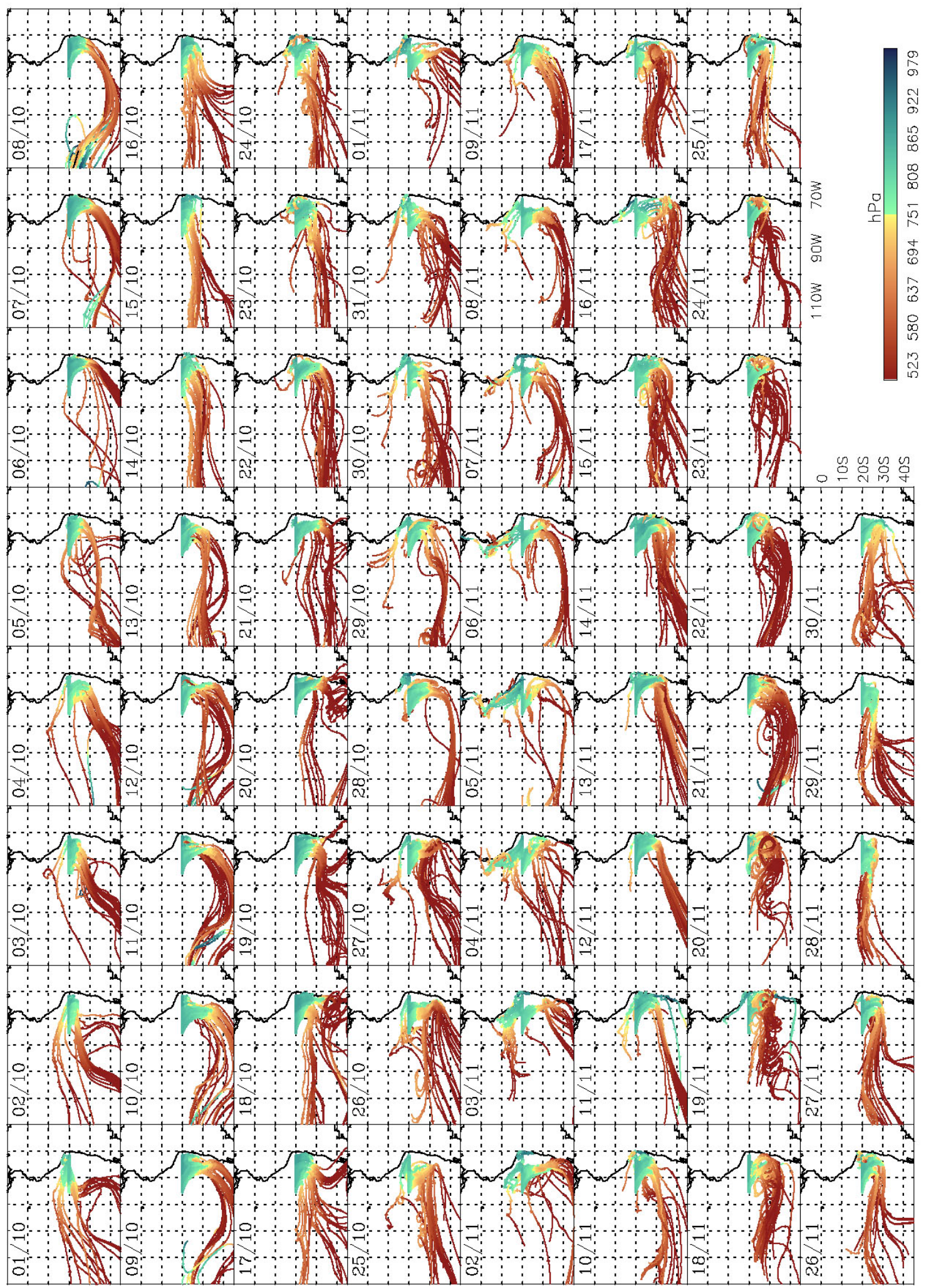

Fig. 15. Ten-day back-trajectories of air reaching $20^{\circ} \mathrm{S}$ between $72^{\circ} \mathrm{W}$ and $85^{\circ} \mathrm{W}$ at a lavel between 20 and $40 \mathrm{hPa}$ above the inversion at 00:00 UTC for each day of October and November 2008 on 23 October 2008. Colour-coding shows the pressure at each point of each trajectory (scale at the bottom). Many trajectories extending zonally along the mid-latitude jet-streams are only visible in their initial portion. The back-trajectories are calculated from sampled ECMWF operational data, truncated at T159, using fourth-order numerical integration with a half-hour time-step, using the service made available by the British Atmospheric Data Centre, 2006-2010 (http://badc.nerc.ac.uk/ data/ecmwf-trj/). 

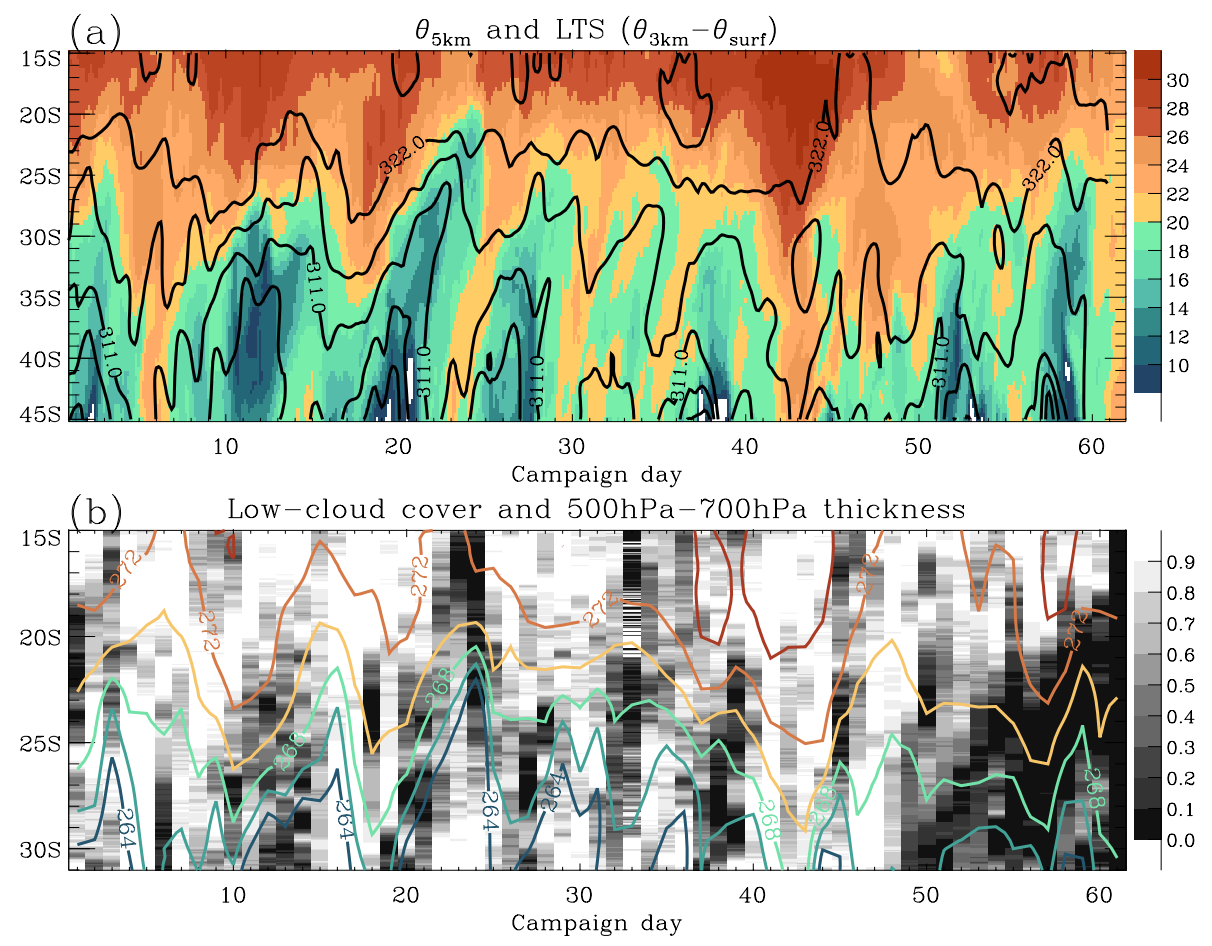

Fig. 16. (a) Hovmüller diagram of lower tropospheric stability $\left(\theta_{700}-\theta_{\text {surf }}\right.$; colour-coding) averaged over $80-85^{\circ} \mathrm{W}$, as a function of time and latitude; the black contours show the potential temperature at $500 \mathrm{hPa}$ over the same zonal average. (b) like (a), but for cloud fraction from GOES at 19:28 UTC (late afternoon), shown as black-and-white filling, and 500-700 hPa thickness contours, shown as coloured contour lines. Thickness and temperature data from UKMO global operational analysis and $3 \mathrm{~h}-21 \mathrm{~h}$ forecasts. The abscissa values indicate the day of the VOCALS-REx campaign, with day 1 corresponding with 1 October and day 61 with 30 November 2008.

To some extent, the back-trajectories of air reaching $20^{\circ} \mathrm{S}$ between 5 and 7 November highlight the circulation in this mid-tropospheric anticyclone. It is interesting to speculate on the possible role of convection over the Amazon and adjacent land. Increased moist convection there and over the Mato Grosso is suggested from satellite OLR maps in the period 18-20 October, and again later between 30 October and 3 November. Such episodic thermal forcing of the midtroposphere may well excite travelling Rossby waves as suggested above. The anomalous upper-level circulation brings tropical, continental air in the vicinity of the MBL in the SEP, in sharp contrast with the usual remote oceanic and subtropical air-mass origin there (cf. Allen et al., 2011). Given the persistent, strong easterly outflow over the low-lying coastal areas of Ecuador, one cannot exclude, in principle, a remote origin from the Amazon basin for some of the air. Considering that South America was anomalously dry compared with climatology (see Fig. 12), and that the events just discussed coincide a period of near-climatological convection, it is possible that air-masses of continental origin over the SEP were anomalously infrequent during the VOCALS-REx campaign.

Dynamical processes at sub-synoptic scales, as discussed e.g. by Munoz and Garreaud (2005), are locally always important near the coast, for example where an approaching mid-latitude disturbance appears to be associated with the development of a distinct coastal anomaly ahead of it (e.g. 2223 October). Similarly, during 15-16 November, following the passage of a mid-tropospheric cyclone across the Andes, a rapid drop in pressure along the coast coincides with extensive coastal clearing. For reasons both of resolution and imperfect representation of the terrain, this dynamics is not captured by either global or regional forecast models (Wyant et al., 2010; Abel et al., 2010), which all appear to miss the coastal cloud anomalies (along with much of the diurnal cycle there). However there is a clear indication from trajectories that become "entangled" with such events that they may considerably prolong the residence time of air-masses above the MBL along $20^{\circ} \mathrm{S}$.

Variability that appears associated with a longer temporal scale is most apparent in the second half of November.

From 19 November onwards, a persistent north-westerly anomaly is seen at $500 \mathrm{mb}$ (Fig. 14c). This feature corresponds to west-north-westerly total mid-tropospheric flow throughout this period, corresponding to a large-scale cyclonic anomaly over the ocean to the west of South America. In spatial coincidence with the strongest poleward flow, reduced large-scale subsidence is diagnosed from the forecast model, consistently with vortex stretching. In the same areas, the day-time cloud images show a band of clearing. The 


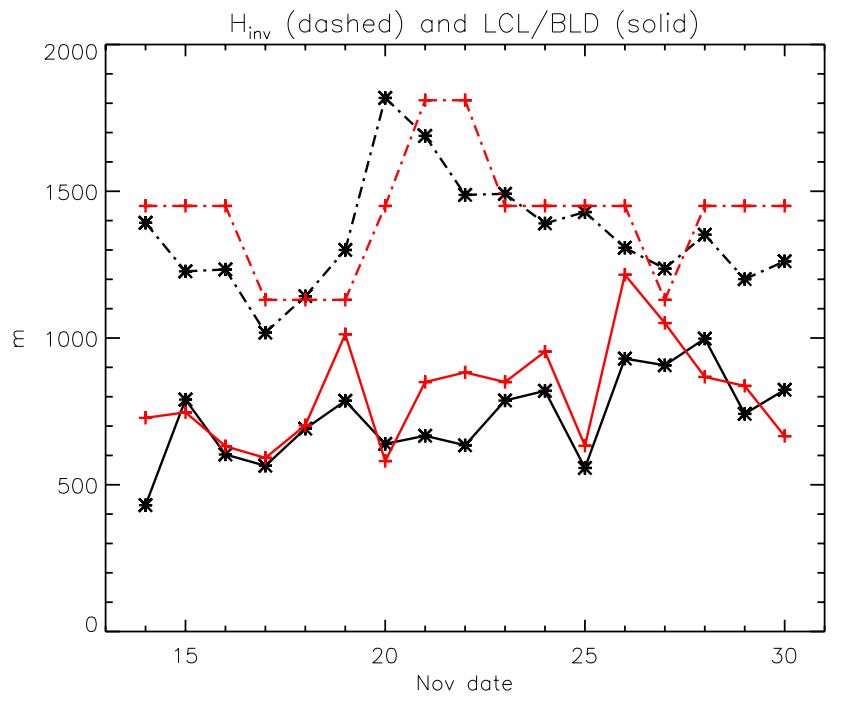

Fig. 17. Inversion height and LCL as estimated from data from R. H. Brown radiosonde launches (black lines), and diagnosed from the UKMO operational forecasts (red lines).

low-pressure centre to the west is part of a slowly evolving wave-train that spans the south-Pacific basin, and appears to emanate from the Maritime Continent, in association with a positive phase of the Madden-Julian Oscillation (MJO), as shown in Sect. 6.

During much of the month of October 2008, changes in cloud cover generally follow a succession of synoptic disturbances travelling through the region, with similar effects during the day and during the night. Cloud cover is generally high, with relatively small differences between night and day (in a few instances even negative over the oceanic area west of $82^{\circ} \mathrm{W}$ ), but is characterised by rapid, near-complete clearing in large, dynamically well-defined areas, dominated by cyclonically turning mid-tropospheric flow, where a combination of cold advection and negative-vorticity advection occurs.

Later in the Spring season, from the end of October to the middle of November, diurnal variations in cloud cover are larger, and on sub-synoptic time-scales coastal and other smaller-scale clearing events (such as those associated with pockets of open cells) become more important. During this period, there is little synoptic activity from mid-latitude depressions, the cloud cover is nearly complete during nighttime, while the day-time break-up, while variable, is never very large, except on 8 November (as discussed above).

As a rough conceptual schematics, one might summarise the previous discussion by dividing the whole of OctoberNovember 2008 into three distinct periods. The first period, until the end of October, has robust synoptic activity from mid-latitude depressions which largely control the cloud conditions. The second period, in the first half of November, shows reduced baroclinic activity, with high values of sea- level pressure, and sub-synoptic scale activity, including influences from continental convection, on time-scales of 2 3 days. The third and final period has moderate synoptic variability, and is dominated by a large-scale circulation anomaly which reduced mid-tropospheric subsidence and allowed for an extensive day-time break-up of the stratocumulus.

Away from the relatively narrow coastal strip, cloud-free areas tend to be zonally aligned and to propagate northwards with the boundary-layer flow. This may be partly due to a memory of the air mass, which being depleted of $\mathrm{CCN}$ once a closed to open cell transition involving precipitation occurs (see e.g. 27/28 October case study of Wood et al. (2011) and associated modelling work by Wang et al. (2010) and Berner and Bretherton (2010)), remains so for a length of time. However, at the latitudes most relevant for VOCALS-REx, synoptic disturbances themselves also tend to travel equatorwards as they approach the barrier of the Andes (see Fig. 16).

\section{Depth of the MBL and variability in oceanic cloud cover on synoptic time-scales}

The operational forecast model of the UK Met Office produces cloud fields which compare well with satellite-derived products in open-ocean areas (Abel et al., 2010, see their Fig. 5). Averaged over the area between $90^{\circ} \mathrm{W}-80^{\circ} \mathrm{W}$ and $15^{\circ} \mathrm{S}-25^{\circ} \mathrm{S}$, the model-derived daily-average low-cloud cover has a correlation of 0.78 (60 points) with that derived from GOES-10. (An identical correlation is found for averages restricted to the zonal strip $90^{\circ} \mathrm{W}-75^{\circ} \mathrm{W}, 19.5^{\circ} \mathrm{S}-$ $20.5^{\circ} \mathrm{S}$ ). We also diagnose an MBL-depth from the model fields, by the level of the MBL-capping inversion (the inversion height, $h_{\text {inv }}$ ). This quantity has a weaker correlation of -0.60 with GOES-10 cloud-top brightness temperatures. The biggest discrepancies occur in late October and early November, when contamination from cirrus cloud (see Fig. 14c) imply that GOES-10 broad-band IR radiances images do not always reliably represent the Sc top. A good agreement is found between the model-derived $h_{\text {inv }}$ and a similarly defined quantity from the profiles returned by shipbased radiosonde ascents (Fig. 17).

The model-diagnosed total low-cloud cover and the inversion height are strongly and negatively correlated (Fig. 18). In general, reduced cloud-cover tends to be associated with elevated cloud-tops, i.e. deep MBLs. As indicated from Fig. 18, direct measurements show a similar correlation. It should be noted that day-to-day variations in cloud cover are most pronounced during daytime, in such a way that the diurnal average cloud cover and its diurnal range are strongly anticorrelated (c.c. around -0.9 on both model-derived and satellite-derived estimates). In general, areas of clouds with shallow MBLs (low $\Delta T$ ) during night-time tend to undergo less day-time break-up. A similar relationship is found with surface solar irradiation. 

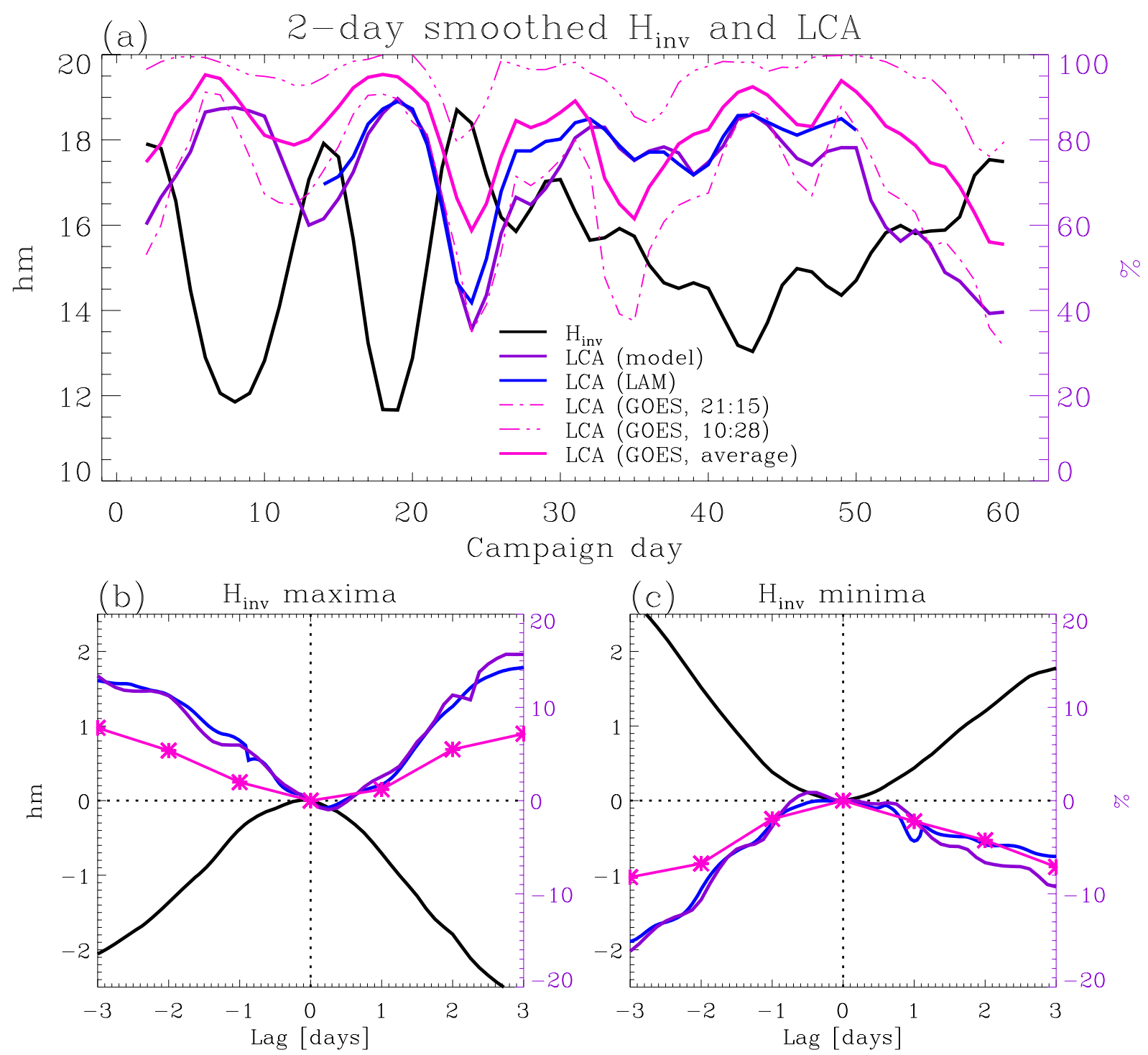

Fig. 18. (a) Inversion height from the UKMO forecast model (full black line) and low-cloud cover, all averaged over the region $90^{\circ} \mathrm{W}-$ $80^{\circ} \mathrm{W}, 15^{\circ} \mathrm{S}-25^{\circ} \mathrm{S}$. The fractional cloud-cover data are shown in violet for the global forecast model, in blue for the limited-area forecast model, and in magenta for the satellite estimates. The thin broken lines show the satellite-derived cloud-cover at 10:28 UTC and 19:28 UTC, respectively; the thicker magenta line is the average. (b) and (c) Composites of inversion height and cloud cover in the region $90^{\circ} \mathrm{W}-80^{\circ} \mathrm{W}$, $15^{\circ} \mathrm{S}-25^{\circ} \mathrm{S}$ based on the extrema of the daily-average MBL depth. Colours denote the same quantities as in panel (a).

Figure 18 also highlights the different character of the three periods identified in the previous section. Until the end of October, cloud-top heights are very variable, with characteristic synoptic temporal and spatial scales. The early part of November, up to the 15th, is generally characterised by low cloud-top heights, especially towards the end; while the second half of November sees higher cloud-tops, prone to day-time break-up. The averages in the area $90^{\circ} \mathrm{W}-75^{\circ} \mathrm{W}$, $19^{\circ} \mathrm{S}-21^{\circ} \mathrm{S}$ are $1569 \mathrm{~m}, 1461 \mathrm{~m}$, and $1587 \mathrm{~m}$ for $h_{\text {inv }}$ for the periods 1-31 October, 1-15 November and 16-30 November, respectively. Correspondingly, the model-derived fractional cloud cover is $0.72,0.80$ and 0.60 , respectively; the satellite-derived values are $0.75,0.78$ and 0.56 , respectively. It thus appears that, over maritime areas, lower inversion heights do generally correspond with increased cloud-cover. A similar statistical correlation was noted in MODIS-derived data by Wood and Hartmann (2006; see also George and Wood, 2010). In coastal areas, observed variations in cloudtop height are smaller and less well correlated with cloud cover. The effects of a strong mean diurnal cycle are also more significant in that region (see Sect. 4). Since the model performance is much weaker on and near land (Abel et al., 2010), we limit our considerations in this section to maritime areas well offshore (more than $300 \mathrm{~km}$ from the coast). 
The UKMO operational model has no representation of cloud-aerosol interaction, and a very rudimentary parametrisation of cloud-microphysical effects. Moreover, its horizontal resolution cannot capture the effect of precipitation on mesoscale dynamics in the MBL. The model does not have any representation of mesoscale or smaller features, including for example the development of pockets of open cells. Thus, its qualitative consistency with observations in both MBL-depth and cloud-cover is non-trivial. Although the model tends to dissipate some cloud with increasing forecast lead time, the simulated day-to-day variability is not solely or primarily due to assimilation increments. Initialised freerunning simulations of the model in one of its climate configurations, HiGAM (Shaffrey et al., 2009), show an evolution of the cloud field in the SEP that remains very close to the operational analyses for up to 10 days. Therefore, the UKMO operational forecasts represent a valuable opportunity to isolate the effects of dynamical forcing on the Sc field in the VOCALS-REx region.

In this model, an elevated inversion consistently corresponds with increased area cloud fraction if averages over a sufficiently large area and away from land are considered. Figure 18 highlights variability with a typical synoptic timescale of about a week or less. However, over the observations period there is no clear indication that this correlation breaks down on longer time-scales. Smoothing the two time-series in Fig. 18 still results in formally significant correlations. Nevertheless, it appears that large-scale circulation anomalies not associated with synoptic-scale systems, which affected VOCALS-REx in the second half of November, when cloud cover was considerably reduced, do play a role. It is apparent, also, that especially intense synoptic events, such as that occurring in 22-24 October, are more than proportionally effective in reducing cloud cover, leaving a signature on longer time-averages. This acquires particular significance when considering that, because of the day-time cloud breakup, the relationship between cloud cover and surface insolation is also skewed in the same sense.

Figure 19 shows the mid-tropospheric circulation anomalies associated with changes in the inversion height in the area $90^{\circ} \mathrm{W}-75^{\circ} \mathrm{W}, 19.5^{\circ} \mathrm{S}-21.5^{\circ} \mathrm{S}$ (indicated by the black rectangle). The composites based on the inversion height $\left(h_{\text {inv }}\right)$ extrema of Fig. 18 indicate that negative (positive) inversion-height anomalies (with positive/negative cloudcover anomalies) coincide with anomalous warm (cold) advection in the FT within anticyclonic (cyclonic) synoptic disturbances when they approach the area of interest. Vertical sections in the meridional plane of these events (not shown) confirm a baroclinic structure, with descent (ascent) associated with a tilted warm (cold) front. Linear correlations with $h_{\text {inv }}$ (not shown) show a very similar, formally significant structure. As may be expected, the associated temperature advection is most intense in the lower free-troposphere just above the MBL.
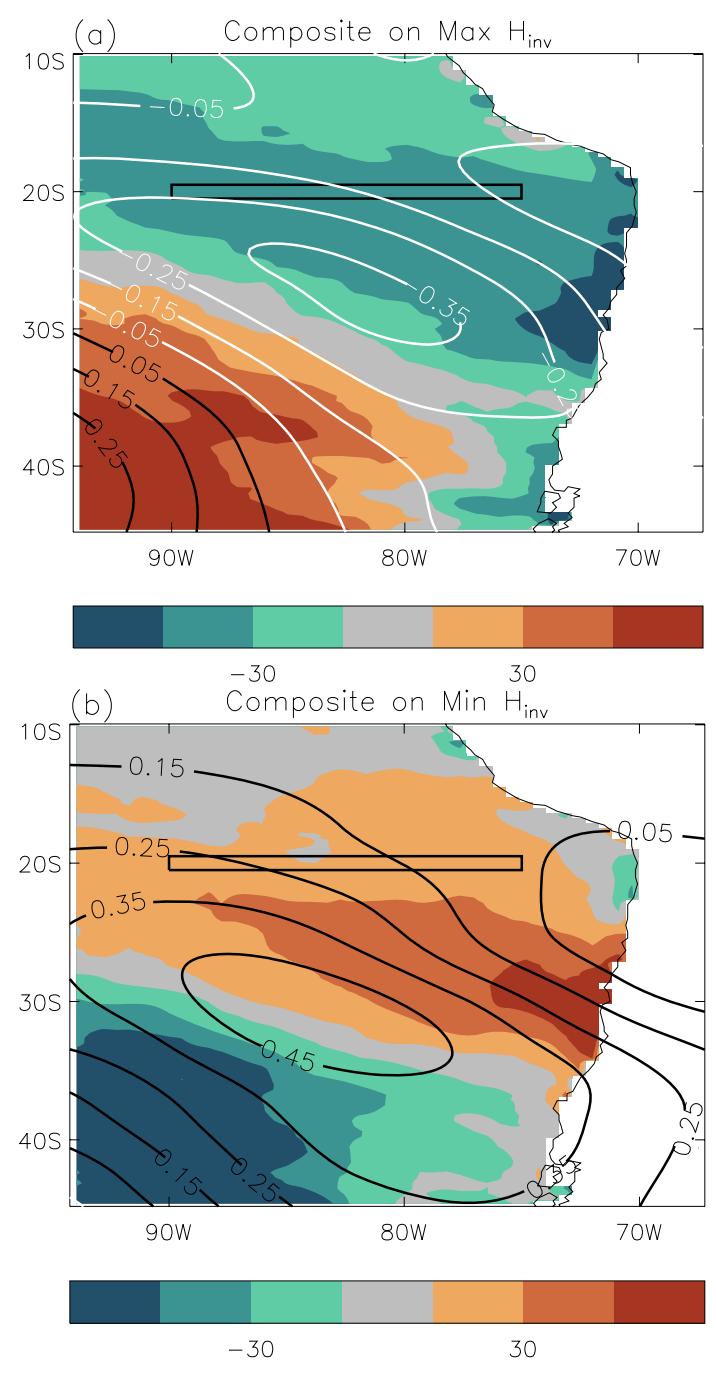

Fig. 19. Composite maps of $50 \mathrm{hm}$ streamfunction anomalies and vertically integrated temperature advection in the FT above the MBL for the positive (panel a) and negative (panel b) extremes in inversion height, $h_{\text {inv }}$, shown in Fig. 18 . The maps show average anomalies over $48 \mathrm{~h}$ prior to the extrema in $h_{\text {inv }}$. Colourcoding refers to heat advection (units are $\mathrm{J} \mathrm{m}^{-2} \mathrm{~s}^{-1} ; 100 \mathrm{~J} \mathrm{~m}^{-2} \mathrm{~s}^{-1}$ roughly correspond to $1 \mathrm{~K} \mathrm{day}^{-1}$ mass-averaged anomalous temperature tendency in the FT). Coutour lines show the streamfunction anomalies, in units of $\mathrm{Mm}^{2} \mathrm{day}^{-1}$. Positive values, marked by black contours, correspond to anticyclonic circulation (apparent in panel b), and negative values for cyclonic circulation. Data from operational analyses and $3 \mathrm{~h}-21 \mathrm{~h}$ forecasts are used.

It appears from Fig. 19 that the cold frontal systems tend to coincide with cyclones at low latitudes, around $30^{\circ} \mathrm{S}$, as they approach the Andean barrier, while the warm fronts tend to occur in association with extratropical storms south of $40^{\circ} \mathrm{S}$. Composites based on the storms themselves (not shown) as they occurred during the period of interest confirm this impression. The leading term in the heat advection anomalies is associated with anomalous vertical motion. Figure 19 
suggest anomalous ascent near the Andean topography associated with synoptic troughing, and anomalous descent associated with synoptic ridging. Note also the association of the latter with advection towards $20^{\circ} \mathrm{S}$ from land areas to the South (cf. discussion on Fig. 15 in the previous section). These results are consistent with the analysis of $\mathrm{Xu}$ et al. (2005) who find that anticyclonic circulation anomalies which tend to reinforce the climatological zonal pressure gradient and generate offshore flow in the lower troposphere off the Chilean coast tend to increase cloud-cover while depressing the inversion and represent an important mechanism in the generation of subseasonal variability in the Sc deck. Painemal and Zuidema (2009) find a similar circulation signature from the cloud droplet-number concentrations with anomalous easterly, offshore flow. In our composites the anticyclonic anomalies also appear to have a more stationary character than the rapidly evolving cyclones, while the latter are associated with the largest vertical wind anomalies.

In general, the height tendencies may be decomposed into a part due to vertical advection, a part due to horizontal advection, and a part due to entrainment, the latter being diagnosed as a residual according to

$\dot{m}_{\epsilon} / \rho=\partial_{t} h_{\text {inv }}+u \cdot \nabla_{2} h_{\text {inv }}-w$,

where all quantities are calculated for $z=h_{\text {inv }}$. Here, $\dot{m}_{\epsilon}$ represent the entrainment flux, $u$ the horizontal wind, and $w$ the vertical wind. This decomposition, shown in the thin lines in Fig. 20, shows a dominant contribution for the inversion height tendencies the area $19.5^{\circ} \mathrm{S}-20.5^{\circ} \mathrm{S}, 90^{\circ} \mathrm{W}-$ $80^{\circ} \mathrm{W}$ by the horizontal advection of height anomalies in the first period of the campaign (1 October to 27 October), to be later partly replaced by a contribution from vertical velocity anomalies. These results are consistent with those of Rahn and Garreaud (2010b), who perform a similar analysis, and demonstrate that horizontal advection gives the leading-order contribution to changes of the MBL depth over synoptic time-scales. As a comparison with Fig. 19 suggests, we find that vertical advection anomalies become markedly more important near the coast, especially to the South, i.e. upstream, of $20^{\circ} \mathrm{S}$. Thus, temperature anomalies in the lower freetroposphere that are generated by the interaction of synoptic systems with the orography are communicated downstream via horizontal advection.

In general, atmospheric heat advection is dominated by the vertical and meridional components, which partially counteract each other. Panel (b) in Fig. 20 highlights the dynamical relationship between vertical velocity anomalies and anomalies of the meridional flow. Initially, a sequence of upperlevel wave cyclones invest the area, with mid-tropospheric ascent and descent associated with poleward and equatorward flow, respectively. On 22 October, a mature baroclinic system marks the transition to a period with reduced synoptic variability but marked activity by baroclinic planetary waves, in which vertical motion is more strongly associated with the

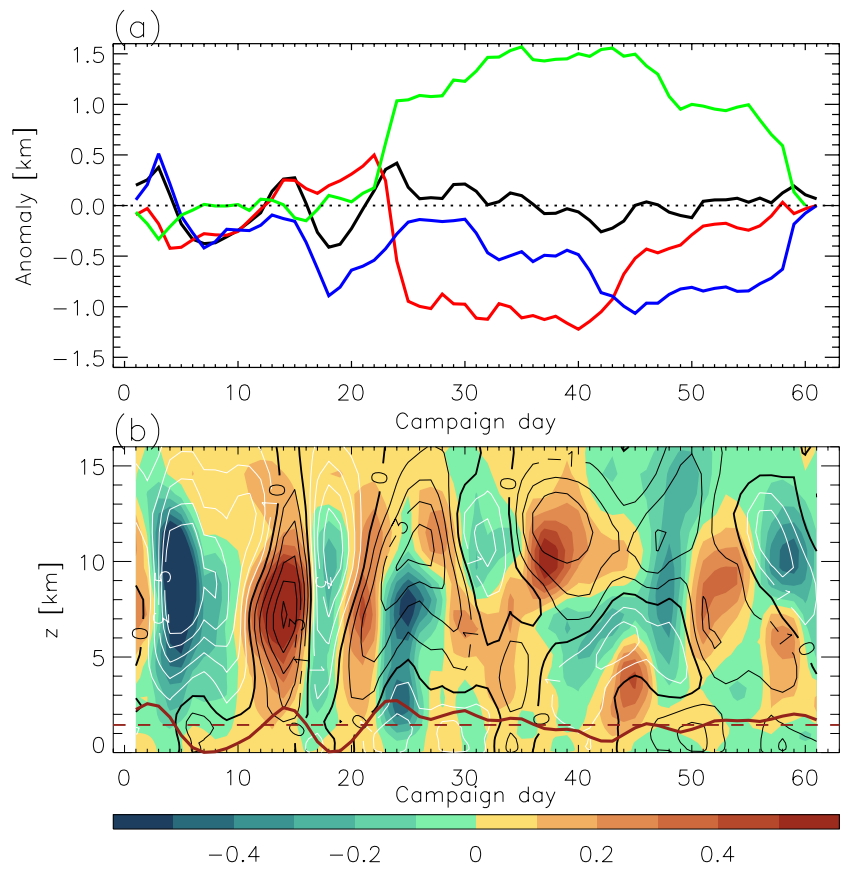

Fig. 20. (a) Time evolution of the $90^{\circ} \mathrm{W}-80^{\circ} \mathrm{W}, 20.5^{\circ} \mathrm{S}-19.5^{\circ} \mathrm{S}$ average inversion height (solid line), compared with the evolution implied by the partial tendencies associated with changes in the vertical velocity only (red line), in horizontal advection only (blue line), and in the residual, interpreted as entrainment (green line). The time-mean values of the partial tendencies were removed. (b) Height-time Hovmueller diagram for the $90^{\circ} \mathrm{W}-80^{\circ} \mathrm{W}$, $20.5^{\circ} \mathrm{S}-19.5^{\circ} \mathrm{S}$ area average meridional (contour lines) and vertical (colour-coding) mass-flux for October-November 2008. Contour interval is $0.5 \mathrm{~kg} \mathrm{~m}^{-2} \mathrm{~s}^{-1}$ for the meridional component, and $0.5 \mathrm{~g} \mathrm{~m}^{-2} \mathrm{~s}^{-1}$ for the vertical component (the transition from cyan to yellow marks the zero line). The height of the inversion is indicated by the dark-red line, the excursions from the mean being exaggerated 3-fold for clarity. A 2-day smoothing is applied to all quantities. Data are from the operational analyses for the inversion height $n$ panel (a), and from both analyses and $3 \mathrm{~h}-21 \mathrm{~h}$ forecasts for all other quantities.

conservation of potential vorticity. At the level of the inversion, the different character of the evolution between the three periods is seen clearly in panel (b) of the Figure. In early November, the induced motion is downward, to switch to anomalous ascent later.

The term in the vertical velocity in Eq. (1) suggests the vertical displacement of a material surface, and horizontal advection near the inversion appears as the advection of MBLdepth (inversion-height) anomalies. Such a picture, however, is misleading. Due to the occurrence of cloud-top entrainment necessary to maintain mass continuity between the large-scale subsidence in the free troposphere and the divergent anticyclonic flow in the MBL, the inversion does not behave like a material surface, or as an isoentropic surface. On synoptic time-scales and shorter, adiabatic processes, i.e. advection, dominate the tendencies in potential 
temperature in the lower FT. MBL temperatures, on the other hand, are closely tied to the more persistent SSTs. The fastest process at hand is represented by diabatic turbulent entrainment across the inversion that controls the location and the structure of the cloud layer. We therefore hypothesise that the mechanism responsible for reduction (increase) in cloud cover with increased (reduced) MBL-depth is increased (reduced) entrainment across the inversion that occurs in response to a cooler (warmer) lower free-troposphere. Entrainment, as diagnosed from the residual, $\dot{m}_{\epsilon}$, from Eq. (1), indeed generally counteracts the tendencies associated with advection. On short time-scales entrainment also correlates with the amplitude of the diurnal cycle in cloud cover, as the main mechanism for cloud destruction. High-pass filtering the time-series of daily values with a 4-day cut-off gives a weak but still significant correlation of 0.3 between $\dot{m}_{\epsilon}$ and the difference between daily maximum and daily minimum cloud cover. On longer time-scales, periods with increased cloud cover also tend to have higher entrainment.

The homogenisation in wet-bulb potential temperature that is seen across the inversion layer in both the model vertical profiles and in radiosonde ascents (not shown) supports the view that the occurrence of buoyancy reversal (e.g., Deardorff, 1980) is instrumental in determining subseasonal variations in cloud-top height in the presence of strong freetropospheric subsidence.

We elaborate on this further. The thermodynamic profiles of the lower atmosphere appear to control the level of the inversion, as it is usually observed to occur at or immediately below the level where the wet-bulb potential temperature reaches a minimum. This result appears confirmed by radiosonde measurements taken from the $\mathrm{R}$. $\mathrm{H}$. Brown research vessel during VOCALS-REx. A natural interpretation for such behaviour is for the inversion to be located where conditions are favourable to cloud-top entrainment mixing, and the concurrent thickening of the MBL can act to balance the divergent surface circulation in the anticyclone.

The location of the minimum in the vertical profile of $\theta_{w}$ may be approximately reconstructed from the profiles of $\theta$ that are characteristic for the mean FT and the mean MBL. In the FT, $\theta$ increases with height, as it does in areas of tropical deep convection with which the subtropical anticyclone is dynamically and advectively connected. Radiative cooling ensures that in the upper FT the temperature profile is slightly steeper than in the deep-convecting tropics; but lower in the FT (below $5000 \mathrm{~m}$ ), the lapse rate deviates very little from the tropics-wide average. In the MBL, $\theta$ is constant up to the cloud base, while in the cloud layer $\theta_{w}$ is approximately constant. The point of intersection between the two resulting profiles of $\theta_{w}(z)$, decreasing in the MBL, and increasing in the FT, may be thought as marking the location of the MBL-top inversion. From these premises one may thus expect that a warming of the MBL, or a cooling of the lower free troposphere, will cause the MBL depth to increase; and conversely.
We thus suggest a general argument for the maintenance of a nearly vanishing jump in $\theta_{w}(z)$ at the inversion, and thus on its location and the variability thereof. Its implication may be formulated in terms of the LTS diagnostics (Fig. 16), consistent with the known correlation between reduced cloud cover and a lower LTS (Klein and Hartmann, 1993; Wood and Hartmann 2006; cf. also Wood and Bretherton, 2006). To some extent, higher LTS can simply reflect the deeper MBL occurring with a cooler lower FT. However, the same jump in RH at constant $\theta_{w}$ does correspond to a smaller jump in dry stability when the temperature is lower, so that higher MBL tops correspond to less stable inversions. This correlation is robustly represented in the operational analysis data.

The assumption under which this argument may hold is that the spatial and temporal scales considered are large enough for an approximate equilibrium, but also small enough that the large-scale constraints on mass and energy conservation remain unchanged. Note that one can't, on the basis of such assumptions, argue about the specific sensitivity of Sc systems to cloud-top entrainment instability compared e.g. with radiative and surface-flux forcing, which is still poorly known but is, in model simulations, highly dependent on the specific formulation of the PBL (Stevens, 2002).

Nevertheless, some support for our speculation is represented by the observed occurrence of weak buoyancy reversal at the inversion in the SEP. An illustration is given in Fig. 21. Panel (a) highlights the tendency for the vertical gradient of $\theta_{w}$ across the inversion to be negative in periods preceding an increase in $h_{\text {inv }}$, especially in October. These anomalies are then advected northwards. The correlation between the entrainment mass flux $\dot{m}_{\epsilon}$ in Eq. (1) and the vertical gradient of $\theta_{w}$ for the area upstream of VOCALS-REx have weak, but marginally significant values for positive lags.

Similarly, the decomposition used in Fig. 20, diagnosed upstream of the VOCALS area between $27^{\circ} \mathrm{S}$ and $30^{\circ} \mathrm{S}$, indicates much larger and sometimes dominant contributions from entrainment, generally opposing vertical motion but sometimes reinforcing them. In general, the tendencies due to horizontal advection are smaller than at $20^{\circ} \mathrm{S}$.

Indirect support for the importance of buoyancy control for the correlation between cloud-cover and inversion height may be obtained from the observational analysis of the cloudy MBL by Zuidema et al. (2009), where an relationship between cloud-top temperatures and inversion height is empirically derived, in the form $T_{i}=T_{s}-\left[6.9\left(h_{\mathrm{inv}} / \mathrm{Km}\right)+\right.$ $0.55] \mathrm{K}$. With air at saturation in a cloudy MBL-top, this results in a relation between below-inversion wet-bulb cloudy potential temperature perturbations and inversion-height perturbation (intended as departures from the time-average) $\delta \theta_{w-} \simeq 3 \delta h_{\text {inv }} \mathrm{K} / \mathrm{Km}$. The free-tropospheric vertical gradient in wet-bulb potential temperature however is, on average, smaller than that, with $\partial_{z} \theta_{w+} \simeq 1.5 \mathrm{~K} \mathrm{Km}^{-1}$. Thus, in response, for example, to a cooling free-troposphere, the MBL must be stabilised either by sinking, which is not observed; 

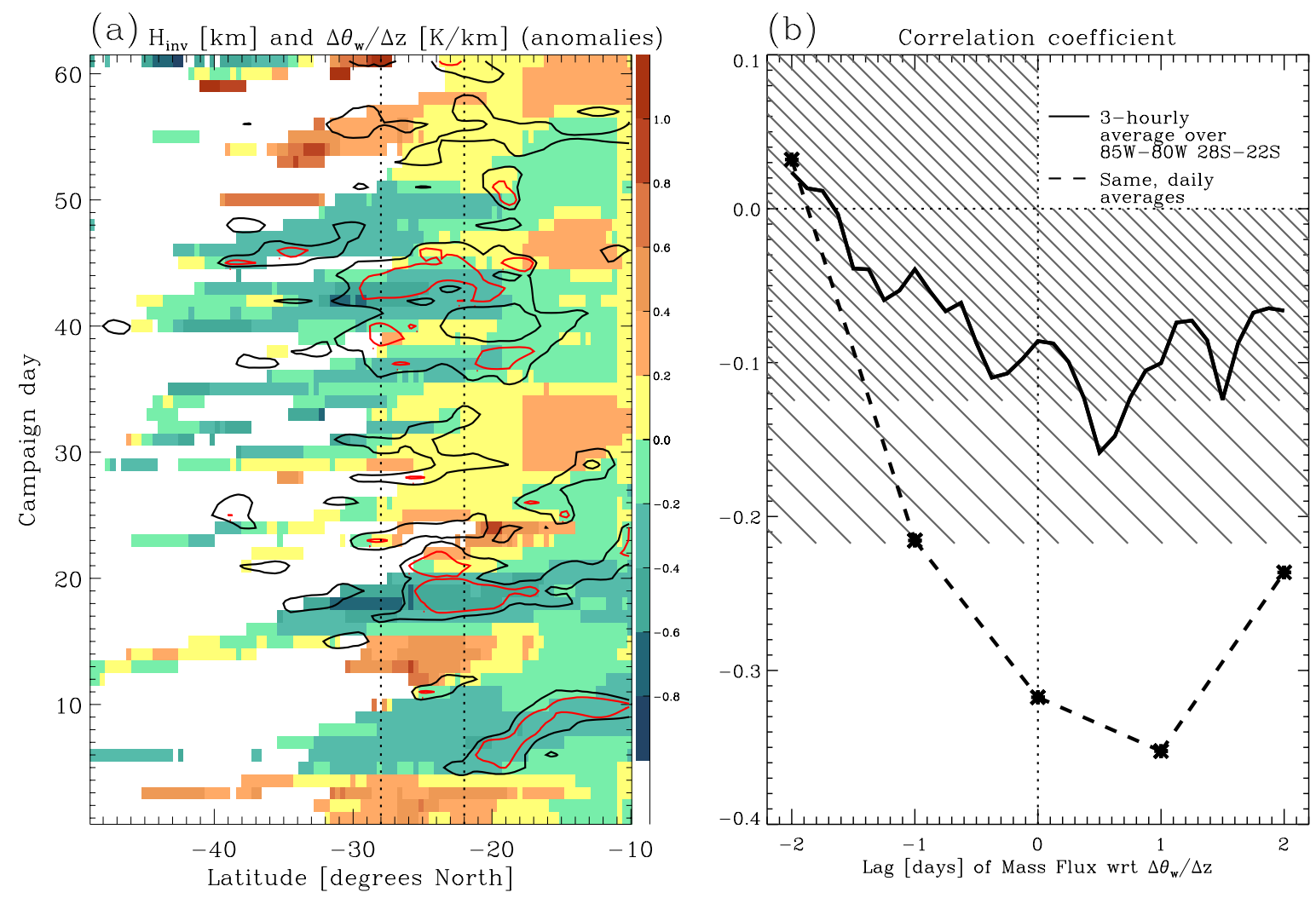

Fig. 21. (a) Hovmüller diagram (latitude along the abscissae, time along the ordinates) of inversion-height daily-mean anomalies (with respect to the mean over October-November 2008), in colours (scale to the right, in $\mathrm{km}$ ). Areas where the an inversion (positive temperature gradient) is not diagnosed are left blank. The black contour lines comprise values below $-0.5 \mathrm{~K} \mathrm{~km}^{-1}$ for the vertical gradient of the wet-bulb potential temperature $\theta_{w}$; the red lines mark values of $-1.5 \mathrm{~K} \mathrm{~km}^{-1}$. All data are averaged between $85^{\circ} \mathrm{W}$ and $80^{\circ} \mathrm{W}$. (b) Lag-correlations of the entrainment mass flux across the inversion and the vertical gradient in wet-bulb potential temperature $\theta_{w}$. Values within the hatched areas are not formally significant (denser hatching applies to the solid line for 3-hourly data).

or by thickening, with a pulse in cloud-top entrainment, and achieving a reduction in $\theta_{w-}$ via a partial cloud break-up.

The required rate of moistening for buoyancyneutralisation also gives a natural scaling for the cloud liquid-water concentration in the cloudy areas proportional to the saturation specific humidity of the air near the inversion, i.e. $q_{l} \sim q_{*}\left(\theta_{\mathrm{PBL}}, p_{\mathrm{inv}}\right)$, where $q_{*}$ is understood as a function of potential temperature and pressure, $\theta_{\mathrm{PBL}}$ is the potential temperature of the MBL (neglecting the thickness of the cloud layer), and $p_{\text {inv }}$ is the pressure height of the inversion. Due to our near-equilibrium assumption, this scaling may be considered for averages over areas much larger than the size of mesoscale circulations and periods of time longer than a few days. By the same token, the average cloud water can be taken as proportional, assuming a given prevalent cloud type, to the areal cloud fraction. The resulting relationship between PBL quantities and cloud cover is illustrated in Fig. 22. The useful correlation values printed in the figure suggest that the $q_{*}$-scaling contains useful information, at least when conditions are cloudy (cloud fraction greater than 0.5), and especially as far as the operational analysis is capable of producing a realistic cloud cover (as also discussed in Abel et al., 2010). More in general, we may propose it here as a first attempt to approximately estimate the contribution from dynamical forcing to the variability of the marine Sc.

To summarise, the evolution of the inversion height is coupled with the changes in cloud-cover, and it may be explained as a combination of fast adjustments on synoptic time-scales, which are partly diabatic and involve a homogenisation of wet-bulb potential temperature across the inversion, and a slower evolution driven by changes in the mean subsidence. The latter is mostly driven by the upper-level circulation, with a strong correspondence between poleward flow and anomalous ascent, as required from potential vorticity conservation.

The response of the inversion height to synoptic forcing has a signature on the surface circulation. The evolution of meteorological parameters at the surface, within the region $90^{\circ} \mathrm{W}-80^{\circ} \mathrm{W}, 25^{\circ} \mathrm{S}-15^{\circ} \mathrm{S}$, is shown in Fig. 23. Panel (a) in the Figure shows the evolution of the pressure difference between the surface and the lower free-troposphere. 

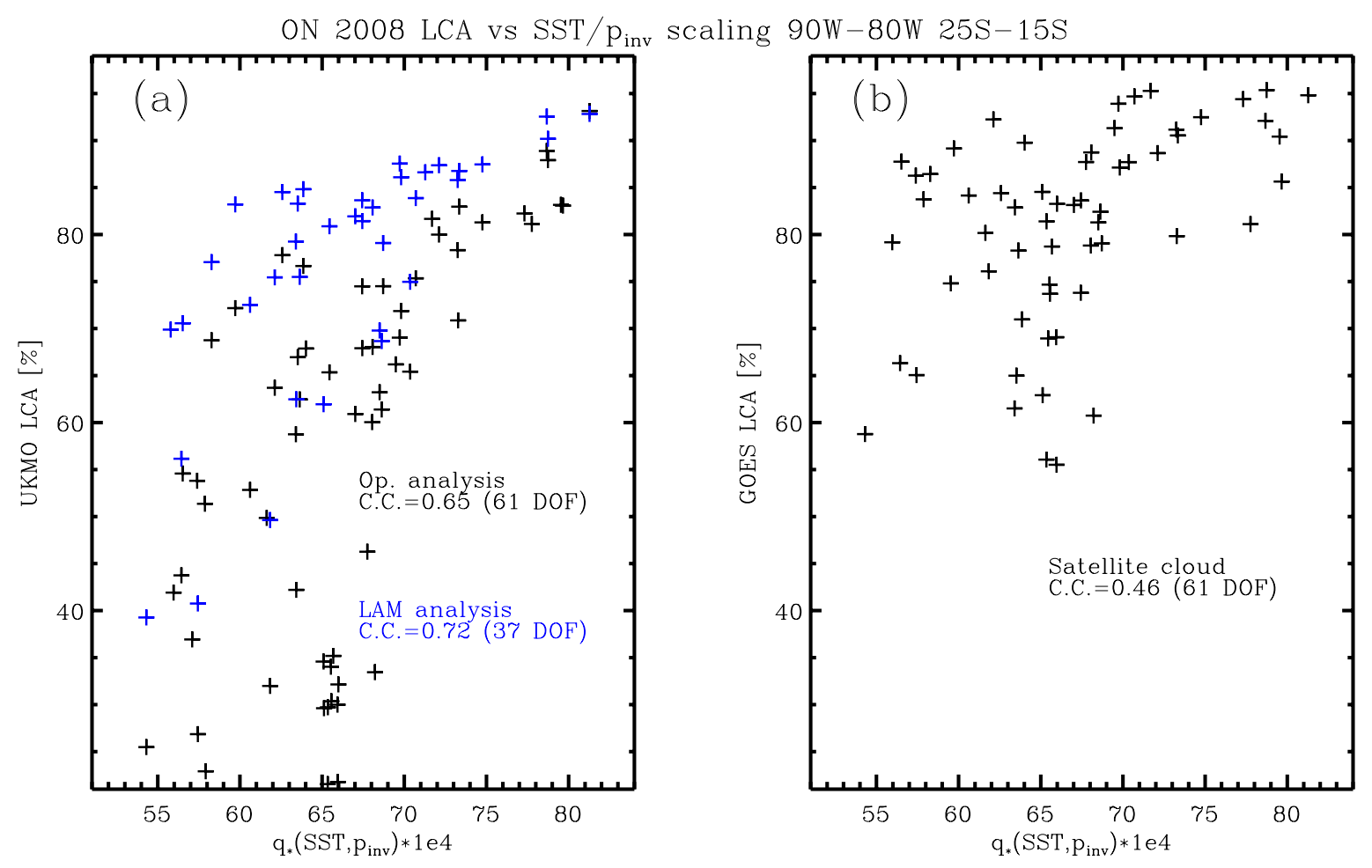

Fig. 22. Scatter-plots of the low cloud fraction average over the area $90^{\circ} \mathrm{W}-80^{\circ} \mathrm{W}, 15^{\circ} \mathrm{S}-25^{\circ} \mathrm{S}$ for each day during October and November 2008, against the $q_{*}$ estimator (see text). The latter is calculated from the operational analyses. (a) Cloud-cover from the global (black crosses) and limited-area (blue crosses) operational analyses. (b) Estimated low-cloud fractions derived from GOES-10 infra-red radiances, as also shown in Figs. 14c and 18; an average value from the 10:28 UTC and the 19:28 UTC fields is used.

This is seen to partly match (with a correlation coefficient of 0.66 for 61 points) the pressure variations that might be expected from changes in the inversion height alone (blue line), when e.g. a thickening of the MBL in response to freetropospheric cooling results in the replacement of a layer of warm free-tropospheric air with cool MBL air. This contribution is important in October during phases of synoptically forced circulation anomalies. From the beginning of November onward, although the correlation with the MBL depth remains large, the contribution from freetropospheric temperatures variations (green line) is dominant. The sum of these two contributions is shown in the red line, which still neglects variations in surface temperature. It may be seen that such approximation is acceptable until mid-November. A different estimator for the thermal wind may be obtained directly from the variations in freetropospheric wet-bulb potential temperature, which reflects both the temperatures changes in the lower free-troposphere, and the associated inversion-height anomalies. These give an approximate relationship between the anomalies that can be written as $p^{\prime} \simeq-2\left(\theta_{w}^{\prime} / \mathrm{K}\right) \mathrm{hPa}$, where the primes indicate departures from the time mean, and appropriate values, diagnosed from the operational analyses $(\Delta \theta=10 \mathrm{~K} ; \theta=300 \mathrm{~K}$; $\partial_{z} \theta_{w}=1.5 \cdot 10^{-3} \mathrm{~K} \mathrm{~m}^{-1}$ ), are substituted for the time-mean quantities. This estimator is shown as the pink line in Fig. 23a. Although its correlation with the actual pressure anomalies is very high ( $c=-0.89$ for $61 \mathrm{DOF})$, it may be noted that it does not perform well in the first part of October, when the adjustment of the inversion to a zero wet-bulb potential temperature jump is incomplete.

Increased surface pressure $\left(p^{\prime}>0\right)$ tends to also correspond to larger surface pressure gradients and thus wind speed. This results in a good correlation of the surface wind speed with the (baroclinic) surface pressure departures from the mean $(c=0.54$ for $61 \mathrm{DOF})$ and a marginally significant one with the free-tropospheric wet-bulb potential temperature departures themselves $(c=-0.34)$. Much of the changes in wind-speed are attributable to the meridional component $(c=0.80)$, as can be seen in Fig. 23b. Presumably because of the additional association between meridional wind and the circulation anomalies highlighted in Fig. 19, this wind component is well-correlated directly with the free-tropospheric potential temperature. Changes in surface-wind direction (green line in Fig. 23b) seem erratic, but remain small, with departures generally less than $10^{\circ}$ from the mean of $143^{\circ}$. The surface wind-speed directly affects air-sea fluxes, and the general weakening of the winds in the second half of November, visible in Fig. 23b, is accom- 

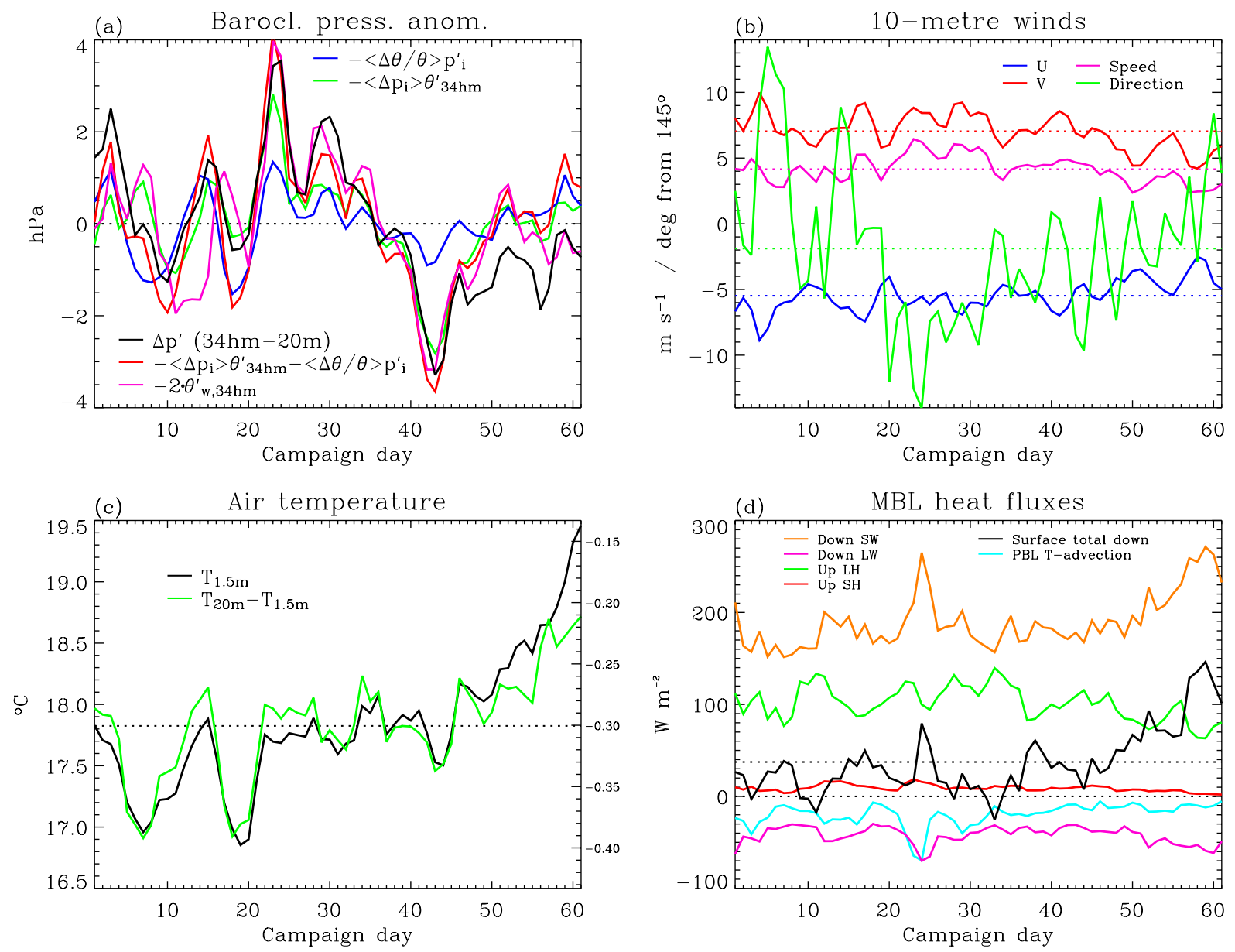

Fig. 23. Daily average MBL quantities diagnosed from the UKMO global operational model for the area $90^{\circ} \mathrm{W}-80^{\circ} \mathrm{W}, 25^{\circ} \mathrm{S}-15^{\circ} \mathrm{S}$ in the period October-November 2008. Day 1 corresponds to 1 October. (a) Pressure difference between $20 \mathrm{~m}$ and $3400 \mathrm{~m}$ (black line) and estimators that neglect surface temperature variations. The blue and the green lines represent contributions from the changes in inversion height and from free-tropospheric temperature changes, respectively. Primes indicate that the time-averages over the period of interest have been subtracted from the relevant quantity. (b) 10-m wind components, wind-speed and wind direction. (c) 1.5-m air temperature (black line, scale on the left-hand side of the panel) and difference between $20-\mathrm{m}$ and $1.5-\mathrm{m}$ air temperatures (green line, scale on the right-hand side of the panel), surface air temperature depression and (d) heat fluxes at the surface, split into radiative and material components, as indicated in the panel. The total downward heat flux is shows in the black solid line. Also shown is the horizontal atmospheric temperature advection, integrated over the depth of the MBL and expressed in $\mathrm{W} \mathrm{m}^{-2}$, in the cyan or light-blue line.

panied by weaker sensible and latent surface heat fluxes. In this part of the period under study, the MBL is affected by a comparatively slow but significant warming of the SSTs.

The air surface temperature undergoes large oscillations in October, becomes fairly stationary between the end of October and the beginning of November, and rises markedly in the second half of November (panel c). The slow evolution largely tracks the SSTs, while the faster oscillations track the changes in atmospheric temperature advection (cyan line in panel d). In the last period, cold MBL advection is reduced, along with a reduction in the meridional wind (panel b) and the meridional SST gradient south of $25^{\circ} \mathrm{S}$ (not shown). The temperature of the air raises to approach that of the underlying ocean, leading to a suppression in latent heat cooling (green line in panel d), which together with the increase in surface solar irradiation (orange line) contribute to the raise in local SSTs. Thus in late November 2008 the large-scale forcing, with weaker surface wind and large-scale subsidence, combines with the response of regional surface meteorology, leading to a reduction of the stability of the MBL and favouring conditions for day-time cloud break-up.

\section{Conclusions}

We have presented an overview of the meteorological conditions in the Sc-covered area of the subtropical anticyclone in the south-east Pacific during the period October- 
November 2008 when the VOCALS-REx intensive observations campaign took place. The region of interest spans an area around the $20^{\circ} \mathrm{S}$ parallel between the coast and $90^{\circ} \mathrm{W}$. As VOCALS-REx was focussed on conditions in the maritime boundary layer (MBL), with its capping inversion and its extensive Sc cloud deck, we chiefly analyse conditions in the lower troposphere and how they varied in dependence of the circulation.

First, we have given an description of the mean circulation in the SEP (Sect. 3), discussing the main processes that regulate the mean winds and thermal structure of the atmosphere, including the MBL inversion. We have highlighted the importance of the subtropical jet stream, of vorticity-balanced winds associated with radiatively and orographically forced vertical motion, and of the thermally direct circulations associated with convection over land. We have also given a brief overview of the mean diurnal cycle (Sect. 4), resulting from a combination of local, radiatively driven changes in the MBL structure, and remotely forced vertical velocity anomalies that propagate into the SEP from the Peruvian and Chilean cordilleras as internal gravity waves (Rahn and Garreaud, 2010a and references therein).

We have then discussed (Sects. 5 and 6) the large-scale context given by the seasonal evolution of the general southern-hemisphere circulation, and the presence and possible significance of interannual and intraseasonal anomalies that interested VOCALS-REx. Between late October and early November there was a southward shift in the overall position of the storm track, as may be expected as part of the normal seasonal evolution. Later, in the second half of November, a quasi-stationary planetary wave pattern developed in the upper troposphere. It had a low centred over the SEP, and it is likely to have originated from convective activity anomalies in the west Pacific associated with an active phase of the Madden-Julian oscillation in the IndoPacific sector. The concurrent anomalies in tropical precipitation and the circulation anomalies in the SEP reflected known patterns of subseasonal variability (Mo and Higgins, 1998; Robertson and Mechoso, 2000). Over the whole of the period of interest, the large-scale SSTs showed a La-Ninalike anomaly pattern. Consistently, the jet-streams were displaced further poleward than usual. At the same time, surface pressure was initially higher than usual in the sub-tropical anticyclone, and weakened to near-climatology later. Thus, the effect of mid-latitude storms on the SEP might have been weaker than usual during the VOCALS-REx period, while the slower seasonal changes were amplified. Convective activity over South America was overall weak compared to the average, but underwent an active phase between late October and early November.

In Sect. 7 we have described the day-to-day meteorology experienced in the SEP during VOCALS-REx. The most striking influence on the subtropical circulation that was observed came from baroclinic disturbances originating in the southern-hemisphere storm track and located or moving north far enough to interact with the Andean orography. As the ridge is oriented in a north-south direction, and spans the depth of the lower half of the cyclones, storms are delayed in its vicinity, gradually weakening on the western side and re-forming on the eastern side of the mountain chain (Vera et al., 2002). During such episodes, significant temperature advection occurred in the mid-troposphere (mostly vertical and meridional). This was associated with large changes in the height of the inversion and strongly affected the cloud fields. Near the coast, along-slope flows associated with the pressure anomalies of the synoptic systems (Xu et al., 2005; Garreaud and Rutllant, 2003) contributed to alter the stratification in the lower troposphere and thus to further affect the cloud. The interaction between sub-tropical cyclones and the Andean orography thus played a significant role for the variability of the Sc deck, and it is of general significance for the climate of the SEP.

Between the end of October and the first half of November a mid-tropospheric anticyclonic anomaly developed to the North of $20^{\circ} \mathrm{S}$, following periods of intensified precipitation over northern South America. The anticyclone moved upstream (westwards), increasing the meridional temperature gradient until cyclone waves appeared at its southern flank, upstream of the VOCALS-REx area. It also caused the advection of air-masses lofted by convection over the continent into the middle and lower troposphere above the SEP, potentially giving a significant contribution to aerosol load and composition there. Given that October and November 2008 overall saw reduced precipitation over South America compared with the climatology, it is possible that events like this are normally more common than was observed during the campaign. A similar, but short-lived effect on air-mass origin in the SEP also resulted from an intense cyclone that occurred between 21-23 October, in association with the strong mid-tropospheric ridging that preceded it. The slower evolution of the MBL inversion and its cloud depended on changes in the large-scale circulation discussed in Sect. 5.

Finally, in Sect. 8 we have shown and discussed the observed link between the amount of low cloud present and the heigh of the MBL inversion. The link is consistent with the known relation between low-cloud liquid water and the "lower-tropospheric stability" (LTS) diagnostics (Klein and Hartmann, 1993; Wood and Hartmann, 2006; George and Wood, 2010), as well as with the relationship between the circulation and anomalies in Sc cover over subseasonal timescales (Xu et al., 2005). Consistently with these studies, which indicate a prevalent atmospheric control on the subseasonal variability of the Sc desk, we suggest a regulating role of the stability of the stratification across the inversion, corresponding to the maintenance of a near-vanishing jump in wet-bulb potential temperature. This may facilitate the process of moistening and cooling the air in the lower troposphere that descends into the MBL via cloud-top entrainment. We have shown that this conceptual model results in a crude, but useful approximation for the cloud cover 
given a few large-scale regional parameters (SSTs and tropospheric air temperature), and that it also helps interpreting the surface-pressure variations over the open ocean. Different processes appear to contribute to changes in the inversion height, and the associated cloud cover, over different time-scales. In agreement with the results of Rahn and Garreaud (2010b), in the initial period (until late October) the variability of the MBL inversion was predominantly associated with the horizontal advection of inversion-height anomalies generated upstream. Later, changes in the mean subsidence and in the SSTs became important, and diabatic changes significantly contributed to the changes in cloud cover.

Our treatment and discussion of the meteorology of VOCALS-REx neglects the mesoscale circulations and airmass conditions that have been observed to affect the cloudcover in the SEP. This limitation pertains, in particular, to conditions within a few hundreds of $\mathrm{Km}$ of the southAmerican coast, and to the observed occurrences of so-called "pockets of open cells" (POCs) where Sc cells develop into shallow-cumulus systems and cloud-cover is dramatically reduced. Such features are poorly represented, or entirely absent, in models of the global circulation, due to the complexity and small spatial scales of the terrain in one case, and to likely interactions between the mesoscale dynamics and cloud microphysical and precipitation processes in the other. Given that our discussion focusses on the specific conditions encountered during October-November 2008, a discussion of these features in a statistical sense would exceed to the scope of this work, and we feel it more appropriate to leave such discussion to papers that will include outcomes from research into the relevant meteorological processes which is currently underway. Even ignoring such important features, however, we have shown that on spatio-temporal scales of a few hundreds of $\mathrm{Km}$ and a few days, and bigger, many of the characteristics of the meteorology in the SEP are associated with synoptic and planetary-scale circulations that affect that area of the world.

Acknowledgements. NOAA OI SST V2 data provided by the NOAA/OAR/ESRL PSD, Boulder, Colorado, USA, from their Web site at http://www.esrl.noaa.gov/psd/. T. T. is grateful, for discussions and suggestions, to Paquita Zuidema, to Steve Woolnough, and to members of the Tropical Group at the Department of Meteorology of the University of Reading.

Edited by: R. Weller

\section{References}

Abel, S. J., Walters, D. N., and Allen, G.: Evaluation of stratocumulus cloud prediction in the Met Office forecast model during VOCALS-REx, Atmos. Chem. Phys., 10, 10541-10559, doi:10.5194/acp-10-10541-2010, 2010.

Allen, G., Coe, H., Clarke, A., Bretherton, C., Wood, R., Abel, S. J., Barrett, P., Brown, P., George, R., Freitag, S., McNaughton, C.,
Howell, S., Shank, L., Kapustin, V., Brekhovskikh, V., Kleinman, L., Lee, Y.-N., Springston, S., Toniazzo, T., Krejci, R., Fochesatto, J., Shaw, G., Krecl, P., Brooks, B., McKeeking, G., Bower, K. N., Williams, P. I., Crosier, J., Crawford, I., Connolly, P., Covert, D., and Bandy, A. R.: Southeast Pacific atmospheric composition and variability sampled along $20^{\circ} \mathrm{S}$ during VOCALS-REx, Atmos. Chem. Phys. Discuss., 11, 681-744, doi:10.5194/acpd-11-681-2011, 2011.

Barret, B. S., Garreaud, R. D., and Falvey, M.: Effect of the Andes cordillera on precipitation from a midlatitude cold front, Mon. Weather Rev., 137, 3092-3109, 2009.

Berner, A., Bretherton, C. S., and Wood, R.: Large-eddy simulation of mesoscale dynamics and entrainment around a pocket of open cells observed in VOCALS RF06, Atmos. Chem. Phys. Discuss., 11, 13317-13353, doi:10.5194/acpd-11-13317-2011, 2011

Bretherton, C. S., Uttal, T., Fairall, C. W., Yuter, S. E., Weller, R. A., Baumgardner, D., Comstock, K., and Wood, R.: The EPIC 2001 stratocumulus study, B. Am. Meteorol. Soc., 85, 967-977, 2004.

Bretherton, C. S., Wood, R., George, R. C., Leon, D., Allen, G., and Zheng, X.: Southeast Pacific stratocumulus clouds, precipitation and boundary layer structure sampled along $20^{\circ} \mathrm{S}$ during VOCALS-REx, Atmos. Chem. Phys., 10, 10639-10654, doi:10.5194/acp-10-10639-2010, 2010.

Bony, S. and Dufresne, J.-L.: Marine boundary layer clouds at the heart of tropical cloud feedback uncertainties in climate models, Geophys. Res. Lett., 32, L20806, doi:10.1029/2005GL023851, 2005.

Colbo, K. and Weller, R. A.: The variability and heat budget of the upper ocean under the Chile-Peru stratus, J. Mar. Res., 65, 607637, 2007.

Davies, T., Cullen, M., Malcolm, A., Mawson, M., Staniforth, A., White, A., and Wood, N.: A new dynamical core for the Met Office's global and regional modelling of the atmosphere, Q. J. Roy. Meteor. Soc., 131, 1759-1782, 2005.

de Szoeke, S. P. and Xie, S.-P.: The Tropical Eastern Pacific seasonal cycle: assessment of errors and mechanisms in IPCC AR4 coupled ocean-atmosphere general circulation models, J. Climate, 21, 2573-2590, 2008.

de Szoeke, S. P., Fairall, C. W., Wolfe, D. E., Bariteau, L., and Zuidema, P.: Surface flux observations on the Southeast Tropical Pacific ocean and attribution of SST errors in coupled oceanatmopshere models, J. Climate, 23, 4152-4174, 2010.

Deardorff, J. W.: Cloud top entrainment instability, J. Atmos. Sci., 37, 131-147, 1980 .

Edwards, J. M. and Slingo, A.: Studies with a flexible new radiation code. I: Choosing a configuration for a large-scale model, Q. J. Roy. Meteor. Soc, 122, 689-719, 1996.

Garreaud, R. D. and Muñoz, R.: The diurnal cycle in circulation and cloudiness over the subtropical Southeast Pacific: a modelling study, J. Climate, 17, 1699-1710, 2004.

Garreaud, R. D. and Rutllant, J.: Coastal lows along the subtropical west coast of South America: numerical simulation of a typical case, Mon. Weather Rev., 131, 891-908, 2003.

Garreaud, R. D., Rutllant, J., and Fuenzalida, H.: Coastal lows along the subtropical west coast of South America: mean structure and evolution, Mon. Weather Rev., 130, 75-88, 2002.

George, R. C. and Wood, R.: Subseasonal variability of low cloud radiative properties over the southeast Pacific Ocean, Atmos Chem. Phys., 10, 4047-4063, doi:10.5194/acp-10-4047-2010, 
2010.

Gill, A.E.: Some simple solutions for heat-induced tropical circulation, Q. J. Roy. Meteor. Soc., 106, 447-462, 1980.

Hastenrath, S.: Climate Dynamics of the Tropics, Kluwer, Dordrecht, 1991.

Klein, S. A. and Hartmann, D. L.: The seasonal cycle of low stratiform clouds, J. Climate, 6, 1587-1606, 1993.

Konor, C. S., Boezio, G. C., Mechoso, C. R., and Arakawa, A.: Parameterization of $\mathrm{PBL}$ processes in an atmopsheric general circulation model: description and preliminary assessment, Mon. Weather Rev., 137, 1061-1082, 2009.

Lock, A. P., Brown, A. R., Bush, M. R., Martin, G. M., and Smith, R. N. B.: A new boundary layer mixing scheme. Part I: Scheme description and single-column model tests, Mon. Weather. Rev., 128, 3187-3199, 2000.

Ma, C.-C., Mechoso, C. R., Robertson, A. W., and Arakawa, A.: Peruvian stratus cloud and the tropical Pacific circulation: a coupled ocean-atmosphere study, J. Climate, 9, 1635-1645, 1996.

Madden, R. A. and Julian, P. R.: Description of global-scale circulation cells in the Tropics with a 4050 day period, J. Atmos. Sci., 29, 1109-1123, 1972.

Martin, G. M., Ringer, M. A., Pope, V. D., Jones, A., Dearden, C., and Hinton, T. J.: The physicsal properties of the atmosphere in the new Hadley Centre Global Environment Model, HadGEM1. Part I: Model description and global climatology, J. Climate, 19, 1274-1301, 2006.

Matsuno, T.: Quasi-geostrophic motions in the Equatorial area, J. Meteorol. Soc. Jap., 44, 25-43, 1966.

Mo, K. C. and Higgins, R. W.: The Pacific-South American Modes and tropical convection during the Southern Hemisphere winter, Mon. Weather Rev., 126, 1581-1596, 1998.

Munoz, R. C.: Diurnal cycle of surface winds over the subtropical Southeast Pacific, J. Geophys. Res. 113, D13107, doi:10.1029/2008JD009957, 2008.

Munoz, R. C. and Garreaud, R. D.: Dynamics of the low-level jet off the west coast of subtropical South America, Mon. Weather Rev., 133, 3661-3677, 2005.

O'Dell, C. W., Wentz, F. J., and Bennartz, R.: Cloud Liquid Water Path from Satellite-Based Passive Microwave Observations: A New Climatology over the Global Oceans, J. Climate, 21, 17211739, 2008.

Painemal, D. and Zuidema, P.: Microphysical variability in southeast Pacific Stratocumulus clouds: synoptic conditions and radiative response, Atmos. Chem. Phys., 10, 6255-6269, doi:10.5194/acp-10-6255-2010, 2010.

Painemal, D., Garreaud, R. D., Rutllant, J., and Zuidema, P.: Southeast Pacific stratocumulus: high-frequency variability and mesoscale structures over San Felix island, J. Appl. Meteorol. Clim., 49, 463-477, 2010.

Rahn, D. A. and Garreaud, R.: Marine boundary layer over the subtropical southeast Pacific during VOCALS-REx - Part 1: Mean structure and diurnal cycle, Atmos. Chem. Phys., 10, 4491-4506, doi:10.5194/acp-10-4491-2010, 2010a.

Rahn, D. A. and Garreaud, R.: Marine boundary layer over the subtropical southeast Pacific during VOCALS-REx - Part 2: Synoptic variability, Atmos. Chem. Phys., 10, 4507-4519, doi:10.5194/acp-10-4507-2010, 2010 b.

Rawlins, F., Ballard, S. P., Bovis, K. J., Clayton, A. M., Li, D., Inverarity, G. W., Lorenc, A. C., and Payne, T. J.: The Met Office global four-dimensional variational data assimilation scheme, Q. J. Roy. Meteor. Soc., 133, 347-362, 2007.

Reynolds, R. W., Rayner, N. A., Smith, T. M., Stokes, D. C., and Wang, W.: An improved in situ and satellite SST analysis for climate, J. Climate, 15, 1609-1625, 2002.

Richter, I. and Mechoso, C. R.: Orographic influences on subtropical stratocumulus, J. Atmos. Sci., 63, 2585-2601, 2006.

Robertson, A. W. and Mechoso, C. R.: Interannual and interdecadal variability of the South Atlantic convergence zone, Mon. Weather Rev., 128, 2947-2957, 2000.

Rozendaal, M. A., Leovy, C. B., and Klein, S. A.: An observational study of diurnal variations of the marine stratiform clouds, J. Climate, 8, 1795-1809, 1995.

Seleuchi, M. E., Garreaud, R. D., Norte, F. A., and Saulo, A. C.: Influence of sutropical Andes on baroclinic disturbances: a cold front case study, Mon. Weather Rev., 14, 3317-3334, 2006.

Shaffrey, L. C., Stevens, I., Norton, W. A., Roberts, M. J., Vidale, P. L., Harle, J. D., Jrrar, A., Stevens, D. P., Woodage, M. J., Demory, M. E., Donners, J., Clark, D. B., Clayton, A., Cole, J. W., Wilson, S. S., Connolley, W. M., Davies, T. M., Iwi, A. M., Johns, T. C., King, J. C., New, A. L., Slingo, J. M., Slingo, A., Steenman-Clark, L., and Martin, G. M.: UK-HiGEM: The new UK High resolution Global Environment Model. Model description and basic evaluation, J. Climate, 22, 1861-1896, 2009.

Shao, H. and Liu, G.: Detecting drizzle in marine warm clouds using combined visible, infrared, and microwave satellite data, J. Geophys. Res., 109, D07205, doi:10.1029/2003JD004286, 2004.

Simmons, A., Uppala, S., Dee, D., and Kobayashi, S.: ERAInterim: New ECMWF reanalysis products from 1989 onwards, ECMWF Newsletter, 110, 25-35, 2006.

Smith, R.: A scheme for predicting layer clouds and their watercontent in a general-circulation model, Q. J. Roy. Meteor. Soc, 116, 435-460, 1990.

Stark, J. D., Donlon, C. J., Martin, M. J., and McCulloch, M. E.: OSTIA: an operational, high resolution, real time, global sea surface temperature analysis system. Oceans '07 IEEE Aberdeen, Conference Proceedings, Marine challenges: coastline to deep sea, Aberdeen, Scotland, 2007.

Stevens, B.: Entrainment in stratocumulus topped mixed layers, Q. J. Roy. Meteor. Soc., 119, 2663-2689, 2002.

Takahashi, K. and Battisti, D. S.: Processes controlling the mean Tropical Pacific precipitation pattern. Part I: the Andes and the Easter Pacific ITCZ, J. Climate, 20, 3434-3451, 2006.

Toniazzo, T.: Climate variability in the south-eastern tropical Pacific and its relation with ENSO: a GCM study, Clim. Dyn., 34:1093-1114, doi:10.1007/s00382-009-0602-z, 2010

Vera, C. S., Vigliarolo, P. K., and Berbery, E. H.: Cold season synoptic-scale waves over subtropical South America, Mon. Weather Rev., 130, 684-699, 2002.

Wang, H., Feingold, G., Wood, R., and Kazil, J.: Modelling microphysical and meteorological controls on precipitation and cloud cellular structures in Southeast Pacific stratocumulus, Atmos. Chem. Phys., 10, 6347-6362, doi:10.5194/acp-10-6347-2010, 2010.

Wilson, D. R. and Ballard, S. P.: A microphysically based precipitation scheme for the Meteorological Office Unified Model, Q. J. Roy. Meteor. Soc, 125, 1607-1636, 1999.

Wood, R. and Bretherton, C. S.: On the relationship between strat- 
iform low cloud cover and lower-tropospheric stability, J. Climate, 19, 6425-6432, 2006.

Wood, R. and Hartmann, D. L.: Spatial variability of liquid water path in marine low cloud: the importance of mesoscale cellular convection, J. Climate, 19, 1748-1764, 2006.

Wood, R., Bretherton, C. S., and Hartmann, D. L.: Diurnal cycle of liquid water path over the subtropical and tropical oceans, Geophys. Res. Lett., 29, 2092, doi:1029/2002GL015371, 2002.

Wood, R., Köhler, M., Bennartz, R., and O’Dell, C.: The diurnal cycle of surface divergence over the global oceans, Q. J. Roy. Meteor. Soc., 135, 1484-1493, 2009.

Wood, R., Mechoso, C. R., Bretherton, C. S., Weller, R. A., Huebert, B., Straneo, F., Albrecht, B. A., Coe, H., Allen, G., Vaughan, G., Daum, P., Fairall, C., Chand, D., Gallardo Klenner, L., Garreaud, R., Grados, C., Covert, D. S., Bates, T. S., Krejci, R., Russell, L. M., de Szoeke, S., Brewer, A., Yuter, S. E., Springston, S. R., Chaigneau, A., Toniazzo, T., Minnis, P., Palikonda, R., Abel, S. J., Brown, W. O. J., Williams, S., Fochesatto, J., Brioude, J., and Bower, K. N.: The VAMOS Ocean-Cloud-Atmosphere-Land Study Regional Experiment (VOCALS-REx): goals, platforms, and field operations, Atmos. Chem. Phys., 11, 627-654, doi:10.5194/acp-11-6272011, 2011.
Wyant, M. C., Wood, R., Bretherton, C. S., Mechoso, C. R., Bacmeister, J., Balmaseda, M. A., Barrett, B., Codron, F., Earnshaw, P., Fast, J., Hannay, C., Kaiser, J. W., Kitagawa, H., Klein, S. A., Köhler, M., Manganello, J., Pan, H.-L., Sun, F., Wang, S., and Wang, Y.: The PreVOCA experiment: modeling the lower troposphere in the Southeast Pacific, Atmos. Chem. Phys., 10, 4757-4774, doi:10.5194/acp-10-4757-2010, 2010.

$\mathrm{Xu}, \mathrm{H}$. , Xie, S.-P., and Wang, Y.: Subseasonal variability of the Southeast Pacific stratus cloud deck, J. Climate, 18, 131-142, 2005.

Zheng, Y., Shinoda, T., Kiladis, G. N., Lin, J., Metzger, E. J., Hurlburt, H. E., and Giese, B. S.: Upper-ocean processe under the stratus cloud deck in the Southeast Pacific Ocean, J. Phys. Oceanogr., 40, 103-120, 2010.

Zuidema, P., Painemal, D., de Szoeke, S., and Fairall, C.: Stratocumulus cloud-top height estimated and their climatic implications, J. Climate, 22, 4652-4665, 2009. 